\title{
Rahmenkonzept Ebolafieber
}

\section{Vorbereitung auf Maßnahmen in Deutschland}


Ansprechpartner:

Robert Koch-Institut

Zentrum für Biologische Gefahren und Spezielle Pathogene

ZBS 7 - Strategie und Einsatz

ZBS7@rki.de

Das Rahmenkonzept Ebolafieber wurde erstmals 2014 aus Anlass des Ebolafieber-Ausbruchs in Westafrika erstellt unter Mitwirkung von und in Abstimmung mit den Obersten und Oberen Landesgesundheitsbehörden, dem Ausschuss für Biologische Arbeitsstoffe (ABAS), der Deutschen Gesellschaft für Infektiologie (DGI), der Deutsche Gesellschaft für Tropenmedizin, Reisemedizin und Globale Gesundheit e.V. (DTG), der Deutschen Gesellschaft für Hygiene und Mikrobiologie (DGHM), der Gesellschaft für Virologie (GfV), der Deutschen Vereinigung zur Bekämpfung der Viruskrankheiten (DVV), dem Paul-Ehrlich-Institut (PEI), dem Bundesinstitut für Arzneimittel und Medizinprodukte (BfArM), dem Ständigen Arbeitskreis der Kompetenz- und Behandlungszentren für Krankheiten durch hochpathogene Erreger (STAKOB), dem Nationalen Referenzzentrum für tropische Infektionserreger am Bernhard-Nocht-Institut für Tropenmedizin Hamburg (BNITM) und dem Konsiliarlabor für Filoviren am Institut für Virologie der Universität Marburg. 


\section{Inhaltsverzeichnis}

1. Ziele

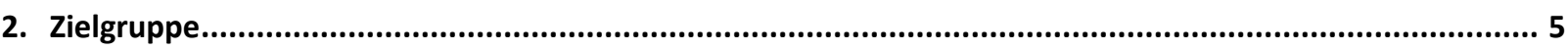

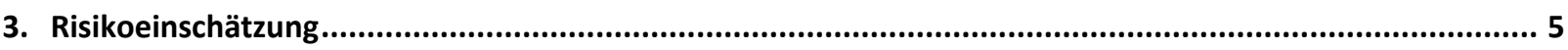

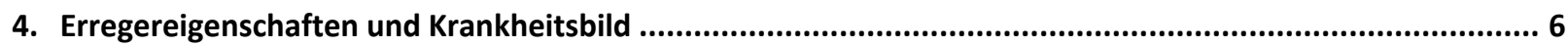

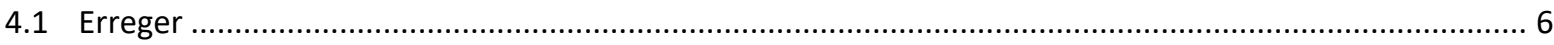

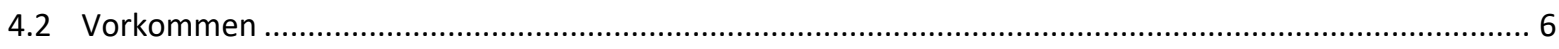

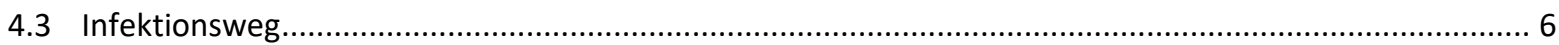

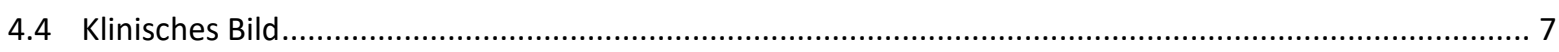

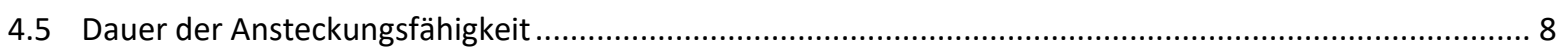

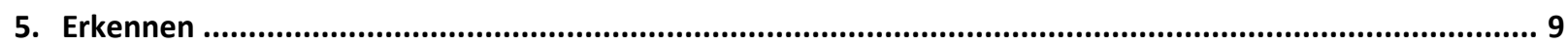

5.1 Klinisches Vorgehen bei Verdacht auf Ebolafieber und erste Maßnahmen ......................................... 9

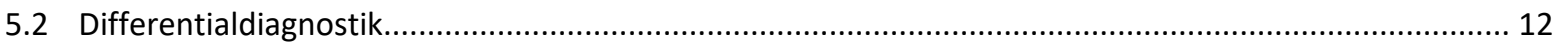

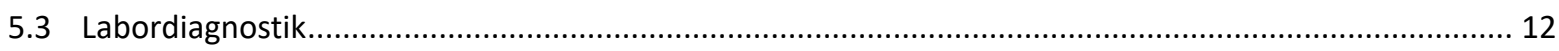

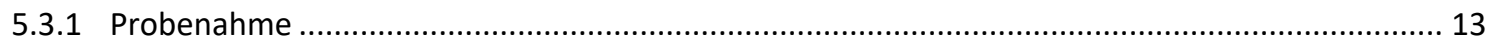

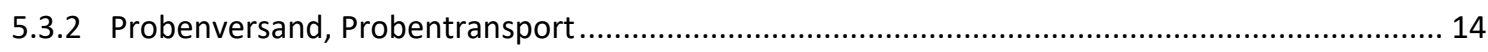

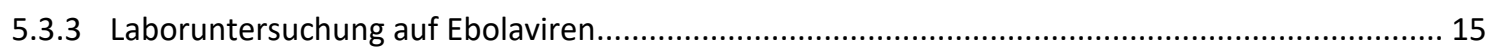

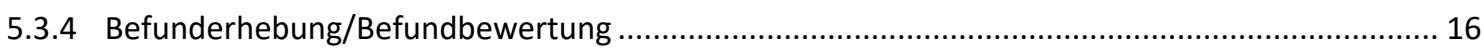

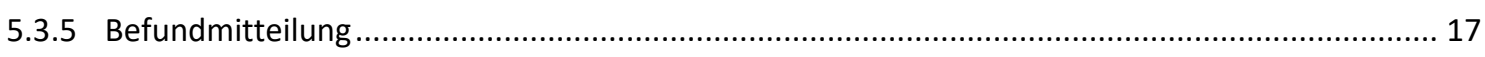

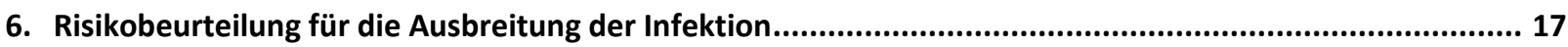

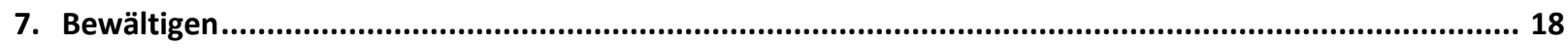

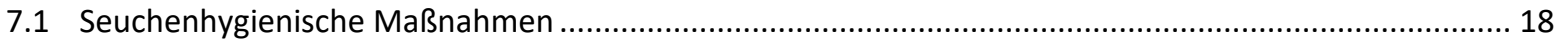

7.1.1 Meldung gemäß Infektionsschutzgesetz (IfSG) und gemäß des Gesetzes zur Durchführung der Internationalen Gesundheitsvorschriften (2005) (IGV-DG) ................................................... 18

7.1.2 Umgang mit symptomfreien Kontaktpersonen (Ansteckungsverdächtigen) ............................. 19

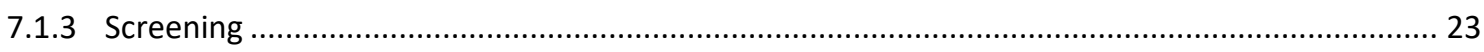

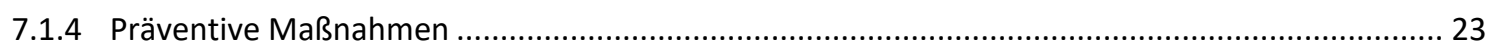

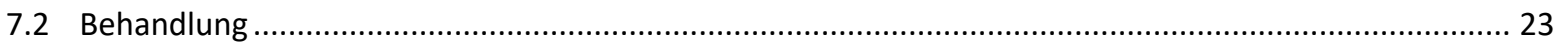

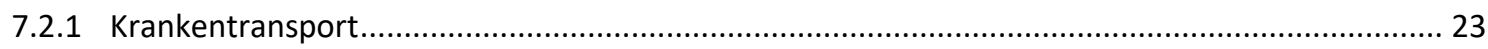

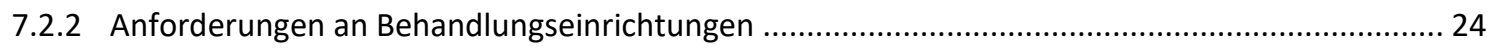

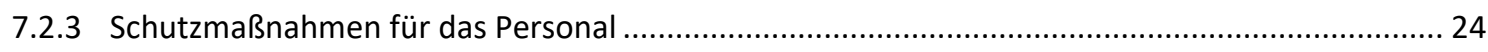

7.2.3.1 Krankenversorgung in Sonderisolierstationen ............................................................ 25

7.2.3.2 Krankenversorgung außerhalb von Sonderisolierstationen ............................................ 25

7.2.3.3 An- und Ablegen der persönlichen Schutzausrüstung................................................. 26

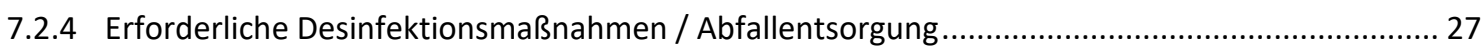

7.2.4.1 Händedesinfektion, Hautdesinfektion, Schleimhautdesinfektion.................................... 28

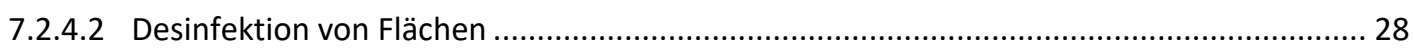

7.2.4.3 Desinfektion von Medizinprodukten (Instrumente und Geräte) .................................... 29

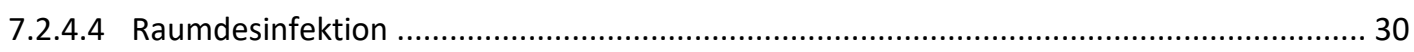

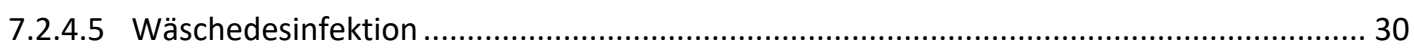

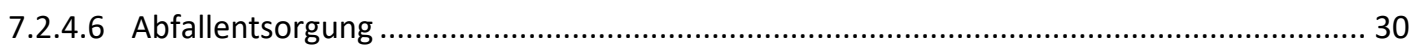

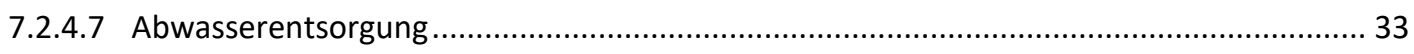

7.2.4.8 Entsorgung des verwendeten Desinfektionsmittels................................................... 34

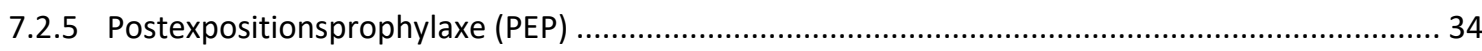

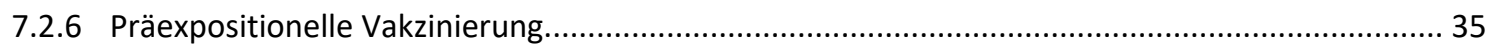

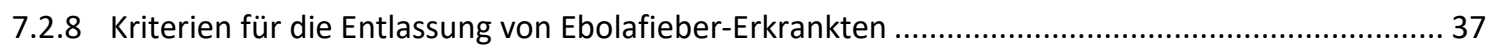

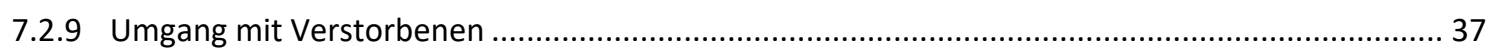

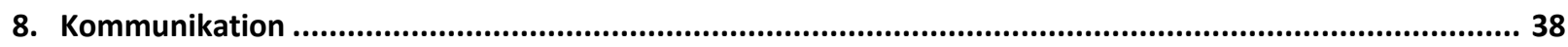

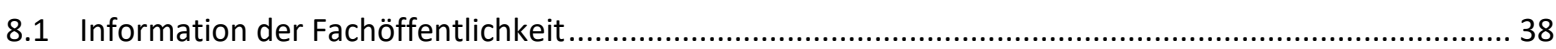

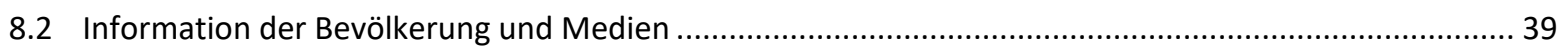




\section{Redaktioneller Hinweis}

In der vorliegenden Fassung (Stand: 17.11.2022) wurden Aktualisierungen gegenüber der Vorversion mit Stand 01.03.2019 unter folgenden Abschnitten vorgenommen: 4.1, 4.2, 4.5, $5.3,6,7.1,7.2,8.2,9$, Anlage C, J.

Vorherige Aktualisierungen erfolgten am 01.03.2019, 24.03.2016, August 2015, März 2015

Die Aktualisierungen beziehen sich ausschließlich auf Aktualisierungen zum wissenschaftlichen Kenntnisstand (z.B. bzgl. Impfstoff und Therapien, Dauer der Ansteckungsfähigkeit), Konkretisierungen und sprachliche Korrekturen. Es sind keine Änderungen enthalten, die sich auf das Vorgehen in Deutschland auswirken.

Erstveröffentlichung erfolgte am 01.12.2014 


\section{Ziele}

Dieses Rahmenkonzept dient dem Erkennen, Bewerten und Bewältigen des Auftretens von Ebolafieber in Deutschland. Je frühzeitiger und stringenter Verdachtsfälle abgeklärt und seuchenhygienische Maßnahmen ergriffen werden, desto größer ist die Wahrscheinlichkeit, dass Sekundärfälle vermieden werden können bzw. deren Zahl geringgehalten werden kann.

Dieses Rahmenkonzept fasst die vorhandenen Informationen, Empfehlungen und Regelungen zum seuchenhygienischen und klinischen Management von Erkrankungen an Ebolafieber in Deutschland zusammen. Gleichzeitig wurden die Rechtsvorschriften der Biostoffverordnung (BioStoffV) zu technischen, organisatorischen und persönlichen Schutzmaßnahmen im Rahmenkonzept berücksichtigt. Das Rahmenkonzept ist ein sich ständig fortentwickelndes Dokument.

Das Rahmenkonzept beschreibt die Abläufe, Aufgaben und Zuständigkeiten im Falle des Auftretens von Ebolafieber-Fällen in Deutschland.

\section{Zielgruppe}

Das Rahmenkonzept richtet sich vor allem an den öffentlichen Gesundheitsdienst (Gesundheitsämter, Obere und Oberste Landesgesundheitsbehörden, Obere und Oberste Bundesbehörden) sowie medizinisches Fachpersonal in der klinischen, ambulanten und rettungsdienstlichen Versorgung in Deutschland. Es beleuchtet darüber hinaus die Schnittstellen des öffentlichen Gesundheitsdienstes mit anderen Einrichtungen, so z. B. Polizei, Feuerwehr, Technisches Hilfswerk, Hilfsorganisationen.

\section{Risikoeinschätzung}

\section{Im Überblick:}

- Das Risiko einer Einschleppung von Ebolafieber nach Deutschland ist sehr gering.

- Im Falle einer Einschleppung wären Sekundärinfektionen in Deutschland in geringer Zahl im engen Umfeld einer erkrankten Person möglich.

- Eine ausgedehntere Weiterverbreitung in der Bevölkerung in Deutschland ist nahezu ausgeschlossen.

Das Risiko einer Einschleppung von Ebolafieber, verstanden als Einreise eines mit EbolavirusInfizierten mit anschließender Weiterverbreitung des Erregers in Deutschland, ist sehr gering.

Das Risiko einer Einschleppung von Ebolafieber besteht praktisch nur, wenn es irgendwo zu einem Ausbruch von Ebolafieber kommt, da sich nur dann Personen über Kontakt mit an Ebolafieber Erkrankten oder Verstorbenen infizieren können. Selbst bei dem bislang größten Ausbruch von Ebolafieber 2014/15 in Westafrika war die Wahrscheinlichkeit der Einreise eines EbolafieberErkrankten nach Deutschland als sehr gering einzuschätzen und es kam nicht dazu.

Im Falle einer Einschleppung von Ebolafieber nach Deutschland wäre eine geringe Anzahl von Sekundärinfektionen im engen Umfeld von an Ebolafieber erkrankten Personen grundsätzlich möglich. Eine darüberhinausgehende Weiterverbreitung des Ebolavirus in der Bevölkerung in Deutschland wäre auch in diesem Falle nahezu auszuschließen, da in Deutschland alle 
Voraussetzungen zur stringenten Unterbrechung von Infektionsketten und zur sicheren Versorgung Betroffener gegeben sind.

\section{Erregereigenschaften und Krankheitsbild}

\subsection{Erreger}

Das Ebolavirus gehört zur Familie der Filoviridae. und wird in fünf Spezies unterteilt: Zaire, Sudan, Taï Forest, Bundibugyo und Reston. Drei der bisher bekannten Spezies des Ebolavirus haben größere Krankheitsausbrüche beim Menschen ausgelöst (Zaire, Sudan, Bundibugyo). Wegen des klinischen Verlaufs wird das Ebolavirus zu den Viren gezählt, die sog. virale hämorrhagische Fieber (VHF) hervorrufen können. Große Teile der Erkenntnisse zu Ebolafieber, gerade in Bezug auf klinische Symptome, Impfstoffe und Therapeutika, wurden im Rahmen des Westafrika-Ausbruchs von Ebolafieber 2013-2016 gewonnen. Dieser Ausbruch wurde durch das Zaire-Ebolavirus hervorgerufen.

Die Erkenntnisse zu anderen humanpathogenen Stämmen (Sudan, Bundibugyo, Tai-Forest) von Ebolavirus sind begrenzter, Epidemiologie und erforderliche Maßnahmen aber vergleichbar. Im Falle eines Ausbruchs von Ebolafieber, welches nicht durch den Stamm Zaire-Ebolavirus hervorgerufen ist, sollte aber in Bezug auf Klinik, Impfstoffe und Therapeutika, ergänzende Literatur hinzugezogen werden.

\subsection{Vorkommen}

Es handelt sich um vergleichsweise seltene Erkrankungen. Größere Ausbrüche von Ebolafieber wurden seit 1976 in der Demokratischen Republik Kongo (vormals Zaire), der Republik Kongo, im heutigen Südsudan, Uganda und Gabun verzeichnet (Chronologie der Ausbrüche des CDC, $\underline{\text { History of }}$ Ebola Virus Disease (EVD) Outbreaks).

Im März 2014 wurde ein Ende 2013 begonnener Ausbruch, hervorgerufen durch das ZaireEbolavirus, im westafrikanischen Guinea bekannt. Von dort breitete sich das Geschehen auf weitere Nachbarstaaten aus und entwickelte sich zum größten bislang erfassten Ebolafieber-Ausbruch. Reiseassoziiert wurden Ebolafieber-Infektionen auch bei Fällen außerhalb Afrikas in den USA und im Vereinigten Königreich festgestellt, und es kam zu Folgefällen nach Behandlung von EbolafieberErkrankten in Spanien und den USA. Dieser Ebolafieber-Ausbruch wurde von der WHO in Guinea im Dezember 2015, in Liberia im Januar 2016 und in Sierra Leone im März 2016 für beendet erklärt. Zu Redaktionsschluss (15.11.2022) betrifft ein von der Ebolavirus-Spezies Sudan hervorgerufener Ausbruch Teile von Uganda.

\subsection{Infektionsweg}

Das Reservoir des Ebolavirus ist nicht eindeutig gesichert. Als Überträger werden Menschenaffen und vor allem Fledertiere (Flughunde, Fledermäuse) vermutet. Infektionen des Menschen entstehen durch Kontakte zu infizierten Tieren, z. B. durch Jagd, Zerlegung, Zubereitung und Verzehr von Wildtieren (sog. „bush meat“).

Eine Übertragung von Mensch zu Mensch ist durch den direkten Körperkontakt mit an Ebolafieber erkrankten oder verstorbenen Menschen und durch den Kontakt mit deren Blut oder anderen Körperflüssigkeiten bzw. Ausscheidungen möglich. Die Infektiosität steigt mit zunehmender Viruslast im Krankheitsverlauf an, insbesondere mit Auftreten der , wet phase' (vermehrte 
Ausscheidung von Körperflüssigkeiten durch Erbrechen, Durchfall, Blutungen). Eine Studie zu einer Gruppe von Ebolafieber-Erkrankten aus Liberia (Chertow et al. 2014) konnte keine Ansteckung in der frühen febrilen Phase der Infektion vor Einsetzen der gastrointestinalen Symptome belegen. Es gibt bisher keine Hinweise auf eine Übertragung von Filoviren von Mensch zu Mensch als Aerosol durch die Atemluft.

Bei Erkrankten, die stark erbrechen bzw. an starkem Durchfall leiden, besteht jedoch die Gefahr der Freisetzung von infektiösen Tröpfchen. Deswegen ist aus präventiver Sicht das Tragen von Atemschutz bei engem Kontakt mit solchen Erkrankten notwendig (siehe Kapitel 7.2.3.2).

Ebolaviren können außerhalb des Körpers einige Tage infektionsfähig bleiben. Eine Ansteckung über Gegenstände wie Spritzen, Matratzen o. ä., die mit infektiösen Körperflüssigkeiten kontaminiert sind, ist daher möglich. Auf trockenen Oberflächen oder solchen, die dem Sonnenlicht ausgesetzt sind, wird das Virus schneller inaktiviert.

\subsection{Klinisches Bild}

Nach einer Inkubationszeit von zwei bis 21 Tagen (im Median 8-9 Tage) beginnt Ebolafieber mit unspezifischen Symptomen wie Fieber, Kopf- und Muskelschmerzen und großer Müdigkeit (frühe febrile Phase) (Tabelle 1).

Wenige Tage nach Krankheitsbeginn kommen Übelkeit, Erbrechen, Durchfall und Oberbauchschmerzen hinzu (gastrointestinale Phase) (Tabelle 1). Bei einigen Erkrankten kommt es zusätzlich u. a. zum Auftreten einer Konjunktivitis, Pharyngitis, eines Schluckaufs, Deliriums und makulopapulösen Exanthems.

Im weiteren Verlauf können hämorrhagische Erscheinungsbilder mit multiplen Blutungen auftreten. Betroffen sind vor allem der Gastrointestinaltrakt, die Lunge und das Zahnfleisch. Beim Ausbruch 2014-2015 in Westafrika fanden sich allerdings nur bei einem kleinen Teil der Erkrankten Hämorrhagien.

Nach der gastrointestinalen Phase kommt es bei einigen Fällen zu einer langsamen Verbesserung des Krankheitszustandes, bei anderen zu einer Verschlimmerung des Krankheitsbildes mit Entwicklung des klinischen Bildes einer metabolischen Azidose aufgrund eines schweren hypovolämischen Schocks.

\begin{tabular}{|c|c|c|}
\hline \multicolumn{3}{|c|}{ Klinisches Bild der Ebolafieber-Erkrankung } \\
\hline Krankheitsphase & $\begin{array}{l}\text { Zeit seit Symp- } \\
\text { tombeginn }\end{array}$ & Klinisches Bild \\
\hline Frühe febrile Phase & Tag $0-3$ & Fieber, Unwohlsein, Müdigkeit, Gliederschmerzen \\
\hline $\begin{array}{l}\text { Gastrointestinale } \\
\text { Phase }\end{array}$ & Tag $3-10$ & $\begin{array}{l}\text { Führende Symptomatik: epigastrische Schmerzen, Übelkeit, } \\
\text { Erbrechen, Durchfall } \\
\text { Begleitsymptome: anhaltendes Fieber, allgemeine Schwäche, } \\
\text { Kopfschmerzen, Bindehaut-Rötung, Brustschmerzen, } \\
\text { Unterleibsschmerzen, Gelenkschmerzen, Muskelschmerzen, } \\
\text { Schluckauf, Delirium }\end{array}$ \\
\hline $\begin{array}{l}\text { Schock oder } \\
\text { Erholung }\end{array}$ & Tag $7-12$ & $\begin{array}{l}\text { Schock: eingeschränktes Bewusstsein oder Koma, schneller } \\
\text { schwacher Puls, Oligurie, Anurie, erhöhte Atemfrequenz } \\
\text { Erholung: Abklingen der gastrointestinalen Symptomatik, oraler } \\
\text { Kostaufbau möglich, zunehmende Belastbarkeit }\end{array}$ \\
\hline $\begin{array}{l}\text { Späte } \\
\text { Komplikationen }\end{array}$ & ab Tag 10 & $\begin{array}{l}\text { Gastrointestinale Blutungen, Sekundärinfektionen*, } \\
\text { Meningoenzephalitis**; }\end{array}$ \\
\hline
\end{tabular}




\begin{tabular}{|c|c|}
\hline $\begin{array}{l}\text { Post-Ebola- } \\
\text { Syndrom }\end{array}$ & $\begin{array}{l}\text { Muskelschmerzen, Kopfschmerzen, Augenbeschwerden, } \\
\text { neurokognitive Residuen }\end{array}$ \\
\hline \multicolumn{2}{|c|}{$\begin{array}{l}\text { * Sekundärinfektionen: Gemeint sind Verdachtsdiagnosen, die auf folgenden klinischen Bildern basieren: Schock, } \\
\text { oraler oder ösophagialer Soor und orale Ulzerationen. } \\
\text { ** Meningoenzephalitis: Gemeint ist eine Verdachtsdiagnose, die auf dem klinischen Bild einer Bewusstlosigkeit } \\
\text { und Nackensteifigkeit basiert. }\end{array}$} \\
\hline
\end{tabular}

Tabelle 1: NEJM, Ebola Virus Disease in West Africa - Clinical Manifestations and Management, 5 November 2014 (Deutsche Übersetzung)

Die Letalität beträgt je nach Virusspezies zwischen 30\% und 90\%. Bei früheren Ausbrüchen der Ebola-Zaire-Virusspezies starben 70-90\% der dokumentierten Erkrankten unter dem Bild eines Multiorganversagens. Beim Ebolafieber-Ausbruch 2014/2015 in Westafrika lag die Letalität bei ca. 60\%. (Garske et al. 2017) Es gibt Anhaltspunkte dafür, dass unter optimaler intensivmedizinischer Betreuung die Letalität deutlich niedriger liegt.

\section{Hinweise zur Therapie finden sich in Kapitel 7.2.7.}

\subsection{Dauer der Ansteckungsfähigkeit}

Eine Weitergabe der Infektion während der Inkubationszeit wurde bislang nicht beschrieben.

Erkrankte sind mindestens solange ansteckend, wie Symptome und eine Virämie bestehen. Dabei korreliert die Ansteckungsgefahr mit der Schwere der Erkrankung. Das Übertragungsrisiko ist somit in der Spätphase der Erkrankung am größten, wenn die Viruslast am höchsten ist, sowie bei Körpern von kurz zuvor Verstorbenen. In Ausbruchsgeschehen findet die Ansteckung häufig über Kontakt mit den Körpern Verstorbener statt (z. B. durch Beerdigungsrituale). In Studien an Ebolavirus-infizierten Makaken wurde infektiöses Virus bis zu sieben Tage nach Todeseintritt nachgewiesen (Prescott et al. 2015).

In Körperflüssigkeiten konnte in mehreren Studien Ebolavirus-RNA nach klinischer Genesung nachgewiesen werden (z.B. Urin bis 30 Tage sowie Schweiß bis 40 Tage nach Symptombeginn). Welche Rolle eine verlängerte Virusausscheidung, z. B. im Urin nach Abklingen der Symptome spielt, ist nicht geklärt. (Moreau et al. 2015, Kreuels et al. 2014, Wolf et al. 2015)

Bei genesenen männlichen Patienten konnte Ebolavirus-RNA in Einzelfällen bis zu 18 Monate nach Beginn der Symptomatik in der Samenflüssigkeit nachgewiesen werden. Eine Ansteckung über Geschlechtsverkehr ist in einem Fall in Liberia sechs Monate nach Beginn der Symptomatik dokumentiert. (Deen et al. 2017, Vetter et al. 2016) Männliche Patienten sollten daher zu den notwendigen Schutzmaßnahmen beraten werden und Kondome erhalten Die WHO empfiehlt männlichen Überlebenden nur geschützten Geschlechtsverkehr (safe sex) bis 12 Monate nach Erkrankungsbeginn (WHO: Ebola virus disease). Verwiesen wird hier auch auf die entsprechende Stellungnahme des Ständigen Arbeitskreises der Kompetenz- und Behandlungszentren für Krankheiten durch hochpathogene Erreger (STAKOB) (www.rki.de/stakob-stellungnahmen). Ob auch genesene Patientinnen Ebolafieber auf sexuellem Wege übertragen können, ist nicht bekannt.

In einer genesenen schwangeren Patientin wurden Ebolaviren im Fruchtwasser nachgewiesen, obwohl die Viren im Blut bereits nicht mehr detektierbar waren (Baggi et al. 2014). Die während einer Geburt oder einem Abort anwesenden Personen haben daher ein erhöhtes Risiko, sich mit Ebolaviren zu infizieren, auch wenn die Schwangere als geheilt gilt. Ebolaviren können in utero auf das Kind übertragen werden, ebenso wie mittels Körperflüssigkeiten während und nach der Geburt. 
Ein weiteres Infektionsrisiko des Kindes besteht durch die Übertragung von Ebolaviren durch Muttermilch auch nach Genesung der Mutter (Bausch et al. 2007). Bei stillenden Frauen, die Ebolavirus-Infektionen überlebt hatten, konnte Ebolavirus-RNA in der Muttermilch bis zu 16 Monate nach Symptombeginn nachgewiesen werden (Keita et al, Open Forum Infect Dis. 2019). Bevor ggf. das Stillen (wieder) aufgenommen wird, sollte nach Empfehlung der WHO die Muttermilch auf Ebolaviren untersucht werden (WHO Guidelines 2020).

Bei einem genesenen Patienten wurden vermehrungsfähige Ebolaviren neun Wochen nach Ende der Virämie im Kammerwasser eines Auges nachgewiesen (Varkey et al. 2015). Bei Eingriffen am Auge besteht daher auch lange nach Genesung ein erhöhtes Risiko, sich mit Ebolaviren zu infizieren. Verwiesen wird hier auch auf die entsprechende Stellungnahme des STAKOB (www.rki.de/stakobstellungnahmen).

Es gibt auch Hinweise, dass Ebolaviren im Liquor längere Zeit überdauern können. Bei einer Patientin in Großbritannien, die nach einem medizinischen Hilfseinsatz in Sierra Leone im Dezember 2014 an Ebolafieber erkrankte, im Januar 2015 geheilt entlassen wurde und im Oktober 2015 an einer Meningitis als Spätfolge der Ebolavirus-Infektion erkrankte, wurden Spuren von Ebolaviren im Liquor nachgewiesen. (CIDRAP 2015, Jacobs et al, Lancet 2016)

Nach den großen Ebola-Ausbrüchen in Westafrika und im Osten der Demokratischen Republik Kongo ist es verschiedentlich zum Wiederaufflammen von Infektionsketten ausgehend von Überlebenden gekommen, die das Virus noch in sich trugen. Neben Fällen von später sexueller Übertragung können solche Events vermutlich auch durch klinische Spätrückfälle ausgelöst werden. Im Fall von Westafrika trat ein solches Event 2021 in Guinea, >5 Jahre nach Ende des großen Ausbruchs 2016, auf (Keita et al, Nature 2021). Die Wahrscheinlichkeit solcher "flare-ups“ ist relativ zur Anzahl Überlebender und somit zur Ausbruchsgröße insgesamt gering.

\section{Erkennen}

\subsection{Klinisches Vorgehen bei Verdacht auf Ebolafieber und erste Maßnahmen}

Der Verdacht auf Ebolafieber muss kritisch geprüft werden. Die klinische Differentialdiagnose zu anderen Tropenkrankheiten, vor allem Malaria, ist aufgrund der anfänglich unspezifischen Symptome nicht einfach (siehe Kapitel 5.2). Entscheidend ist die Erfragung der Reiseanamnese und der Risikokontakte.

\section{Vorgehen}

Die Abklärung von Verdachtsfällen erfolgt zunächst auf der Basis des klinischen Erscheinungsbildes sowie der Reise- und Kontaktanamnese. In den meisten Fällen reicht eine anamnestische Befragung unter Einhaltung von wenigstens 1,5 Metern Abstand zum Erkrankten aus, um zu klären, ob ein begründeter Verdachtsfall vorliegt oder nicht (siehe Anlage A).

Die betroffene Person muss unbedingt darauf hingewiesen werden, dass bei einer Abklärung von Ebolafieber korrekte Angaben lebenswichtig für alle Betroffene (inkl. Kontaktpersonen) sein können: Je früher die medizinische Behandlung beginnt, desto eher können lebensbedrohliche Komplikationen vermieden werden. 
Ergibt die Erstanamnese Hinweise auf einen begründeten Verdacht auf Ebolafieber, so ist sofort das zuständige Gesundheitsamt zu informieren (siehe Kapitel 7.1). Die endgültige Entscheidung, ob ein begründeter Verdachtsfall vorliegt, ist gemeinsam mit dem Gesundheitsamt zu treffen. Dieses berät sich dazu mit dem behandelnden Arzt oder der behandelnden Ärztin und ggf. dem zuständigen Kompetenzzentrum, dem Behandlungszentrum (siehe Anlage B) und der zuständigen Landesgesundheitsbehörde. Bis zur Entscheidung, ob ein begründeter Verdacht vorliegt, sollte der Erkrankte, sofern es sein Zustand zulässt, im derzeitigen Umfeld (zu Hause, Arztpraxis, Aufnahmebereich Krankenhaus) verbleiben.

\section{Kriterien für Vorliegen eines begründeten Verdachts auf Ebolafieber}

Person mit Fieber $\left(>38,5^{\circ} \mathrm{C}\right.$ ), oder erhöhter Temperatur mit Begleitsymptomen (z. B. Durchfall, Übelkeit, Erbrechen, Hämorrhagien),

- Die in den 21 Tagen vor Erkrankungsbeginn Kontakt* mit einem an Ebolafieber Erkrankten, einem Krankheitsverdächtigen oder einem an Ebolafieber Verstorbenen hatte, oder

- Die in den 21 Tagen vor Erkrankungsbeginn im In- oder Ausland in einem Labor oder in einer sonstigen Einrichtung Umgang mit Ebolaviren, erregerhaltigem Material oder Ebolavirusinfizierten Tieren hatte,

oder

- Die sich bis zu 21 Tage vor Erkrankungsbeginn in einem Epidemiegebiet aufgehalten hat, und

dort direkten Kontakt zu Fledertieren (Flughunde, Fledermäuse), nichtmenschlichen Primaten oder deren Ausscheidungen oder dem Fleisch dieser Tiere (z. B. „bush meat“ von diesen Tieren) hatte.

* Kontakt:

- Direkter Kontakt mit Blut oder anderen Körperflüssigkeiten bzw. erregerhaltigem Gewebe von an Ebolafieber Erkrankten bzw. Verstorbenen, begründeten Verdachtsfällen oder möglicherweise Kontakt mit Ebolavirus kontaminierter Kleidung / Gegenständen;

- Ungeschützter Kontakt (<1,50 m) mit einem an Ebolafieber Erkrankten bzw. Verstorbenen oder begründeten Verdachtsfall (inkl. Haushaltskontakte, Flugpassagiere, die neben, vor oder hinter dem Erkrankten saßen (1 Sitz in alle Richtungen, auch über den Gang), ihn betreuende Crewmitglieder);

- Aufenthalt in einem Krankenhaus, in dem möglicherweise Ebolafieber-Erkrankte behandelt wurden.

Kein Kontakt: nur Aufenthalt (> 1,50 m) im gleichen Gebäude/ Raum / Verkehrsmittel.

\section{Schutzmaßnahmen während Abklärung des Verdachts auf Ebolafieber}

Es gelten die folgenden Schutzmaßnahmen bei der anamnestischen Befragung eines Erkrankten mit Erstverdacht auf Ebolafieber:

- Abstand von > 1,50 m zum Erkrankten;

- Kontaktminimierung;

- Allgemeine Hygienemaßnahmen.

Sollte der Gesundheitszustand des Erkrankten neben der Erstanamnese eine körperliche Untersuchung erforderlich machen oder wird ein Kontakt mit Körperflüssigkeiten wahrscheinlich, 
z. B. wenn der Erkrankte erbricht, wird entsprechend ABAS Beschluss 610 (siehe Anlage F) das Tragen folgender persönlicher Schutzausrüstung empfohlen:

- Körperschutz;

- Handschutz;

- Augen- und Gesichtsschutz;

- Atemschutz;

- Fußschutz.

Weiterführende Hinweise zur persönlichen Schutzausrüstung finden sich in Kapitel 7.2.3.2 sowie im ABAS-Beschluss 610 (siehe Anlage F, Kapitel 4.2), in dem detaillierte Beschreibungen der einzelnen Komponenten aufgeführt sind.

Hinweise zur Therapie finden sich in Kapitel 7.2.7.

Hinweise zu Desinfektionsmaßnahmen und Abfall/Abwasserentsorgung finden sich in Kapitel 7.2.4.

\section{Initiale Maßnahmen bei Vorliegen eines begründeten Verdachts auf Ebolafieber}

Wurde in Abstimmung zwischen dem behandelnden Arzt und dem zuständigen Gesundheitsamt ein begründeter Verdachtsfall festgestellt, so ist unter Einbeziehung des STAKOB-Kompetenzzentrums, des STAKOB-Behandlungszentrums (siehe Anlage B) und der zuständigen

Landesgesundheitsbehörde eine sofortige Verlegung des Betroffenen auf eine Sonderisolierstation eines Behandlungszentrums anzustreben. Die Verlegung auf eine Sonderisolierstation sollte bei Erkrankten mit ausgeprägter Symptomatik (z. B. Durchfall, Erbrechen) oder bei einem dringenden Bedarf für eine weitergehende klinische labortechnische Diagnostik und Therapie prioritär erfolgen.

In der Sonderisolierstation erfolgen die Routinelabordiagnostik (point-of-care Diagnostik) und die Veranlassung der Labordiagnostik auf eine Ebolavirus-Infektion und nach Möglichkeit deren Differenzialdiagnosen, insbesondere Malaria (siehe Kapitel 5.2 und 5.3).

Insbesondere bei begründeten Verdachtsfällen, die lediglich eine schwache Symptomatik aufweisen (frühe febrile Phase) und bei denen kein akuter Handlungsbedarf bzw. Bedarf für ein Notfall-Labor besteht, kann das zuständige Gesundheitsamt prüfen, ob der Betroffenen vor Ort verbleiben kann, wenn es sich bei der Örtlichkeit (z. B. Wohnung, Arztpraxis, Notaufnahme) um eine gemäß $\ 30$ IfSC "geeignete Einrichtung" handelt.

Unter diesen Umständen kann in Absprache mit dem zuständigen Gesundheitsamt sowie ggf. dem zuständigen Kompetenz- und Behandlungszentrum erwogen werden, vor Ort Blut abzunehmen und eine umgehende Ebolavirus-Labordiagnostik zu veranlassen.

Weitere Hinweise zu Probenahme, -transport und Labordiagnostik finden sich in Kapitel 5.3.

Die vorübergehende Absonderung des Erkrankten vor Ort sollte unter den Bedingungen eines „barrier nursing“ z. B. im Einzelzimmer (siehe Kapitel 7.2.2) erfolgen. Diese Maßnahme muss bis zum Ausschluss des begründeten Verdachts bzw. bei positivem Labornachweis bis zur Verlegung in die Sonderisolierstation durchgeführt werden.

Bei der Versorgung des Erkrankten ist die in Kapitel 7.2.3.2 genannte Schutzkleidung zu tragen. 


\section{Melde- und Übermittlungsverfahren bei einem begründeten Verdachtsfall}

Ein begründeter Ebolafieber-Verdachtsfall ist als Verdacht auf ein virusbedingtes hämorrhagisches Fieber gemäß \ 6 IfSG durch den behandelnden Arzt namentlich meldepflichtig. Hierzu ist der Arzt von seiner Schweigepflicht entbunden.

Diese Meldungen haben unverzüglich zu erfolgen, müssen dem Gesundheitsamt spätestens 24

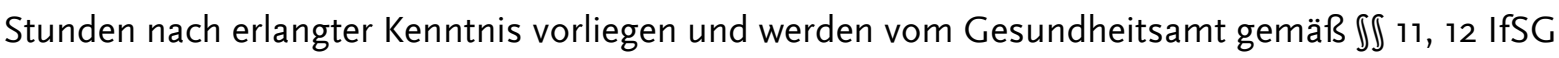
über die zuständigen Landesbehörden an das RKI übermittelt.

\section{Weitere Hinweise finden sich in Kapitel 7.1.1.}

\subsection{Differentialdiagnostik}

Die Abklärung möglicher Differentialdiagnosen sollte vorbereitet werden, um eine verzögerte Therapie bei Vorliegen einer anderen lebensbedrohlichen Krankheit (z. B. Malaria) zu verhindern.

\section{Vorgehen}

Die klinische Differentialdiagnose umfasst die Abgrenzung zu Krankheiten, die ein ähnliches Krankheitsbild aufweisen. Hier ist die Malaria im Hinblick auf Tropenkrankheiten bei Erkrankten mit unklarem Fieber die wichtigste Differentialdiagnose. Aufgrund der hohen Letalität einer Malaria tropica und der guten Behandlungsmöglichkeiten muss eine Malaria-Infektion frühestmöglich abgeklärt bzw. bestätigt werden. Hinweise zur Malaria-Diagnostik für Erkrankte, die außerhalb der Sonderisolierstationen betreut werden, finden sich in Anlage $\mathrm{C}$.

Differentialdiagnostisch kommen eine Reihe weiterer Erkrankungen in Frage: Erkrankungen durch andere Erreger viraler hämorrhagischer Fieber (z. B. Gelbfiebervirus, Lassavirus, Denguevirus, Vertreter von Hantaviren, Krim-Kongo-Virus, Marburgvirus), Hepatitis A, Typhus abdominalis, Pest, Rickettsiosen, Meningokokken-Sepsis bzw. andere Sepsisformen, Leptospirose, hämorrhagische Formen des Rückfallfiebers, bakterielle Ruhr, evtl. auch Intoxikationen. Eine unspezifische Symptomatik kann gerade in der Frühphase z. B. auch durch Influenza, Noroviren oder banale Infekte verursacht sein. Zeitgleiche Infektionen durch mehrere Erreger sind möglich.

Die Differentialdiagnostik sollte in Abstimmung mit den jeweiligen Nationalen Referenzzentren und Konsiliarlaboren erfolgen.

\subsection{Labordiagnostik}

Liegt ein begründeter Verdacht auf Ebolafieber vor (siehe Kapitel 5.1), ordnet das zuständige Gesundheitsamt ggf. nach Rücksprache mit dem zuständigen Kompetenz- und Behandlungszentrum des STAKOB eine geeignete Absonderung des Betroffenen an. Bevorzugt sollte diese auf einer Sonderisolierstation eines Behandlungszentrums erfolgen. Dort sollte auch die Probenahme zur labordiagnostischen Abklärung erfolgen.

Liegen Verdachtsmomente einer Infektion mit Ebolavirus vor, sind nach TRBA 100 alle orientierenden Untersuchungen der Primärprobe mit nicht inaktiviertem Material mindestens unter den Bedingungen der Schutzstufe 3 nach Nummer 5.4.2 durchzuführen. 
Liegen Untersuchungsproben von einer mit Ebolavirus infizierten akut erkrankten Person vor, sind nach TRBA 100 labordiagnostische Untersuchungen mit nicht inaktiviertem Material unter den Bedingungen der Schutzstufe 4 nach Nummer 5.5 durchzuführen (Adressen siehe Anlage D).

Laboruntersuchungen auf Ebolaviren bei asymptomatischen Kontaktpersonen sind nicht angezeigt.

Die Standardlabordiagnostik (z. B. klinische Chemie) und spezifische differentialdiagnostische Laboruntersuchungen (z. B. auf Malaria) sollten bei begründeten Verdachtsfällen dementsprechend in einer Sonderisolierstation (point-of-care-Diagnostik, kleine „Diagnostik-Straße“) durchgeführt werden.

Ist in Ausnahmefällen eine diagnostische Abklärung bei einem Erkrankten erforderlich, der außerhalb einer Sonderisolierstation betreut wird, erfolgt diese in Abstimmung des behandelnden Arztes mit dem zuständigen Gesundheitsamt und ggf. Kompetenz- und Behandlungszentrum. Eine NotfallLabordiagnostik (Standardlabor) kann auch beim isolierten Erkrankten außerhalb der Sonderisolierstationen als point-of-care Diagnostik im Isolierbereich durchgeführt werden. Falls sich der Verdacht bestätigt, sind die dafür verwendeten Geräte anschließend fachgerecht zu desinfizieren oder, falls dies nicht möglich ist, entsprechend zu entsorgen. Persönliche Schutzausrüstung entsprechend Kapitel 7.2.3.2 ist zu tragen.

\subsubsection{Probenahme}

Um einen begründeten Verdacht auf Ebolafieber zu bestätigen oder auszuräumen, oder um den Heilungsverlauf zu dokumentieren, müssen dem Erkrankten Proben für die labordiagnostische Klärung entnommen werden. Bei der Probenahme muss eine Gefährdung des die Probe entnehmenden Personals durch das Tragen adäquater Schutzausrüstung minimiert werden. Aufgrund der dazu notwendigen Schutzmaßnahmen sollte die Probenahme prioritär in einem Behandlungszentrum erfolgen.

\section{Vorgehen}

- Vor dem Versand von Proben einer Person mit begründetem Verdacht auf Ebolafieber erfolgt eine Kontaktaufnahme mit dem Diagnostik-Labor (Laboradressen siehe Anlage D), um die Art und die Anzahl der Proben sowie die Versandmodalitäten abzustimmen.

- Lückenlose Dokumentation der Probenahme (inklusive Personen und Zeiten).

- Die Entnahme von Probenmaterial bei einem begründeten Verdacht auf Ebolafieber bzw. bei einem bestätigten Ebolafieber-Fall erfolgt nur unter Einsatz der erforderlichen persönlichen Schutzausrüstung (siehe Kapitel 7.2.3.2).

- Spezielle Anforderungen an die Technik der Probenahme und die hygienischen Standards erfordern neben Handlungsanweisungen auch praktische Übungen von ärztlichem oder sonstigem Personal für die Probenahme.

- Bei der Verwendung von spitzen und scharfen medizinischen Instrumenten zur Probenahme sind Arbeitsgeräte mit Sicherheitsmechanismen (Sicherheitsgeräte, vorzugsweise mit selbstauslösendem Sicherheitsmechanismus) einzusetzen und diese in einen geeigneten Abwurfbehälter (,sharps container") abzuwerfen (siehe Anlage E Ziffer 4.2.5 Absatz 3 ff.). 
- Probenmaterial: Bevorzugtes Material für die Primärdiagnostik ist Serum oder EDTAVollblut (2 Röhrchen), zum Nachweis der Genesung auch Urin, Stuhl, Samenflüssigkeit, Schweiß, Konjunktival- und Mundschleimhaut-Abstriche.

- An die Entnahme einer Rückstellprobe ist zu denken.

\subsubsection{Probenversand, Probentransport}

Ein reibungsloser und sicherer Probentransport muss gewährleistet sein, um eine schnelle labordiagnostische Klärung zu erreichen und gleichzeitig eine Gefährdung durch unsachgemäß verpacktes Probenmaterial zu verhindern.

Vorgehen

- Vor dem Versand von Proben einer Person mit begründetem Verdacht auf Ebolafieber erfolgt eine Kontaktaufnahme mit dem Diagnostik-Labor (Laboradressen siehe Anlage D), um die Proben anzumelden und die Versandmodalitäten abzustimmen.

- Lückenlose Dokumentation des Probenversands / Probentransports (inklusive Personen, Probenzustand und Zeiten).

- Versand von Diagnostikproben bei begründetem Verdacht auf Ebolafieber als UN 2814 (Klasse 6.2, Kategorie A) gemäß ADR (Europäisches Übereinkommen über die internationale Beförderung gefährlicher Güter auf der Straße); Verpackungsanweisung P620 mit der Kennzeichnung „Ansteckungsgefährlicher Stoff, gefährlich für Menschen, UN-Nr. 2814".

- Die Anwendung der Multilateralen Vereinbarung M315 ermöglicht die Beförderung von Abfällen, die mit Ebolaviren kontaminiert sind, erfordert jedoch einen zusätzlichen Vermerk im Beförderungspapier „Beförderung vereinbart nach Abschnitt 1.5.1 ADR (M315)“.

- Anbringen des für die Gefahrgutklasse 6.2 vorgeschriebenen Gefahrzettels (BiohazardSymbol); Information „Bei Beschädigung oder Freiwerden Gesundheitsbehörden unverzüglich verständigen“ kann zusätzlich angebracht werden.

- Verantwortlich für die Anmeldung der Probe, die ordnungsgemäße Klassifizierung und die Einhaltung der Transportvorschriften (geschultes Personal nach IATA/ADR) ist der Absender, im Zweifelsfall der Leiter der versendenden Einrichtung.

- Bestätigung des Probeneingangs durch das Labor an den behandelnden Arzt / Amtsarzt und den Einsender sofort nach Probeneingang.

- Transport und das Diagnostik-Labor sollten so ausgewählt werden, dass die Probe innerhalb von sechs Stunden im Labor eintreffen und dort sofort untersucht werden kann.

- Verpackung (P620 für ansteckungsgefährliche Stoffe der UN-Nr. 2814):

- Zusammengesetzte Verpackungen, bestehend aus:

1. (Einem) flüssigkeitsdichten Primärgefäß(en),

2. Einer flüssigkeitsdichten Sekundärverpackung,

3. Einer starren Außenverpackung.

Für flüssige Materialien (etwa: Blut) muss saugfähiges Material in einer für die Aufnahme des gesamten Inhalts ausreichenden Menge zwischen Primärgefäß(en) und 
der Sekundärverpackung angeordnet sein. Wenn mehrere Primärgefäße in einer Sekundärverpackung eingesetzt werden, müssen sie entweder einzeln eingewickelt oder voneinander getrennt werden, um eine potenzielle Kreuzkontamination bei evtl. Zerbrechen oder Auslaufen eines Primärgefäßes zu minimieren (weitere Informationen ADR: Bundesgesetzblatt (bgbl.de)-ADR Seite 214, UNECE: R1104-Sw-Kopierer20170512205512 (unece.org), RKI - Probentransport).

- Typgeprüfte Verpackungen sind im Fachhandel erhältlich oder werden vom Kurierdienst gestellt.

- Der Transport erfolgt z. B. durch die Firmen World Courier (Deutschland) GmbH, CMKLogistik Breisach oder weitere entsprechend ADR geschulte Transporteure. Wenn der Transport durch den Kurierdienst nicht zeitnah sichergestellt werden kann, kann dieser ggf. per Notfalltransport (z. B. Rettungsdienst, Feuerwehr oder Polizei) erfolgen (entsprechende Absprachen sind möglichst bereits im Vorfeld zu treffen). Die Notfallbeförderung zur Rettung menschlichen Lebens oder zum Schutz der Umwelt ist von den Vorschriften des ADR freigestellt, sofern alle Maßnahmen zur völlig sicheren Durchführung dieser Beförderung getroffen worden sind.

\subsubsection{Laboruntersuchung auf Ebolaviren}

Eine erste orientierende labordiagnostische Untersuchung auf Ebolaviren bei begründeten Verdachtsfällen kann in einem geeigneten Labor der Schutzstufe 3 (S3-Labor) erfolgen (TRBA100 4.4.1 (4)). Bei bestätigten Ebolafieber-Fällen muss die Laboruntersuchung in einem Schutzstufe 4Labor (S4-Labor) erfolgen (Laboradressen siehe Anlage D).

\section{Vorgehen}

- Die Diagnostik erfolgt in der Regel durch real-time PCR zum Nachweis des Virusgenoms im Blut (Serum oder Plasma) während der akuten Krankheitsphase.

- Nachweise von spezifischen Antikörpern (IgM, IgG) mittels IF, ELISA, NT sind möglich, jedoch in der Akutdiagnostik nicht aussagekräftig.

- Die Bestätigung eines positiven Erstbefundes in der real-time PCR erfolgt durch PCRAmplifikation einer weiteren Region des Virusgenoms mit derselben Nukleinsäureprobe oder Sequenzierung des PCR-Produktes.

- Eine Anzucht von Ebolaviren ist zur Bestätigung nicht notwendig. Sie kann nur aus nicht inaktiviertem Probenmaterial erfolgen und ist nur in Laboratorien der Schutzstufe 4 erlaubt (Laboradressen siehe Anlage D). Die Anzucht kann dort angestrebt werden, um das Virus für weitere Charakterisierungen zu vermehren. Grundsätzlich spielt die Anzucht von Ebolaviren in der Primärdiagnostik eine untergeordnete Rolle.

- Bei negativem Bestätigungstest ist die Untersuchung mit einer Rückstellprobe zu wiederholen.

- Mit dem Untersuchungsergebnis ist innerhalb von 6-8 Stunden nach Probeneingang im Diagnostiklabor zu rechnen, falls keine unvorhergesehenen technischen Probleme auftreten. 
Erste orientierende Untersuchung auf eine Ebolavirus-Infektion in einem geeigneten S3Labor

Ist eine erste orientierende Untersuchung außerhalb von Schutzstufe 4-Laboren erforderlich, sollte diese nur in Absprache mit dem zuständigen Gesundheitsamt und ggf. STAKOB-Kompetenzzentrum erfolgen.

Solche diagnostischen Erstuntersuchungen mittels real-time PCR können nach Biostoffverordnung (BioStoffV) in Verbindung mit der TRBA 100 „Schutzmaßnahmen für Tätigkeiten mit biologischen Arbeitsstoffen in Laboratorien“ (GMBI. Nr. 51/52 vom 17. Oktober 2013, S. 1010-1042; 1. Änderung: GMBI. 2014 Nr. 38 vom 30. Juni 2014, S. 814) der Schutzstufe 3 zugeordnet werden:

"4.4.1 (4) Liegen Verdachtsmomente einer Infektion mit einem biologischen Arbeitsstoff der Risikogruppe 4 vor, sind alle orientierenden Untersuchungen der Primärprobe mit nicht inaktiviertem Material mindestens unter den Bedingungen der Schutzstufe 3 durchzuführen.“

Weitere Informationen finden sich in Anlage $G$.

Die orientierende Untersuchung auf Ebolaviren in Schutzstufe 3-Laboren kann z. B. erfolgen, wenn das Vorliegen eines begründeten Verdachtsfalls anders nicht ausgeräumt werden kann (aktuelle Laboradressen siehe Anlage D).

Geeignet sind Labore, die folgende Bedingungen erfüllen:

- Betrieb eines virologischen Schutzstufe 3-Labors, in dem der Schutz des Personals sichergestellt ist,

- Erfahrung in der molekularen Diagnostik viraler Erkrankungen,

- Verwendung kommerzieller Kits zum Nachweis von Ebolavirus-RNA, welche eine Extraktions- und Amplifikationskontrolle beinhalten (z. B. von Altona Diagnostics, Roche Diagnostics etc.),

- Erfolgreiche Teilnahme an Ringversuchen zur externen Qualitätskontrolle der EbolavirusPCR-Diagnostik.

Bei positivem Erstbefund sollte parallel zur Bestätigungsdiagnostik die Versendung der Rückstellprobe an das Konsiliarlabor für Filoviren, Institut für Virologie, Klinikum der PhilippsUniversität Marburg, an das Nationale Referenzzentrum für tropische Infektionserreger, BernhardNocht-Institut für Tropenmedizin Hamburg, oder an das WHO CC emerging pathogens and biological threats (WHO CC für neu auftretende Pathogene und biologische Gefahren), Robert KochInstitut erfolgen.

\subsubsection{Befunderhebung/Befundbewertung}

Abhängig vom Zeitpunkt der Probenahme bei einem Verdachtsfall, führen folgende Algorithmen zum Untersuchungsergebnis:

1. Die Blutentnahme ist $>48$ Stunden nach Einsetzen der mit Ebolafieber zu vereinbarenden Symptomatik erfolgt:

- Erstuntersuchung und Bestätigungsdiagnostik sind positiv:

$\rightarrow$ Ebolavirus-Infektion nachgewiesen. 
- Erstuntersuchung ist negativ:

$\rightarrow$ Ebolavirus-Infektion nicht nachgewiesen.

2. Die Blutentnahme ist $\leq 48$ Stunden nach Einsetzen der mit Ebolafieber zu vereinbarenden Symptomatik erfolgt:

- Erstuntersuchung und Bestätigungsdiagnostik sind positiv:

$\rightarrow$ Ebolavirus-Infektion nachgewiesen.

- Die Erstuntersuchung ist negativ und der Erkrankte erfüllt weiterhin die Kriterien für einen begründeten Verdachtsfall:

$\rightarrow$ Es sollte eine Differentialdiagnostik durchgeführt werden.

$\rightarrow$ Der Erkrankte wird für den Zeitraum bis zu 48 Stunden nach Einsetzen der Symptomatik weiterhin isoliert, aber nicht notwendigerweise auf der Sonderisolierstation (siehe Kapitel 7.2.2 und Kapitel 7.2.3). (Das erste negative Testergebnis auf Ebolaviren senkt die Wahrscheinlichkeit einer Ebolafieber-Erkrankung erheblich, so dass unter Umständen (z. B. bei gleichzeitiger Besserung der Symptomatik) in diesem Fall eine Isolierung außerhalb der Sonderisolierstation ausreichend ist). Bei der Versorgung des Erkrankten ist die in Kapitel 7.2.3.2 genannte Schutzkleidung zu tragen.

$\rightarrow$ Ungeachtet einer labor-bestätigten Differentialdiagnose sollte eine weitere Probe des Erkrankten auf Ebolavirus untersucht werden, die frühestens am 3. Tag (> 48 Stunden) nach Einsetzen der mit Ebolafieber zu vereinbarenden Symptomatik genommen wird.

Erstuntersuchung dieser Probe ist in der PCR negativ:

$\rightarrow$ Ebolavirus-Infektion nicht nachgewiesen.

Erstuntersuchung und Bestätigungsdiagnostik sind positiv:

$\rightarrow$ Ebolavirus-Infektion nachgewiesen.

\subsubsection{Befundmitteilung}

Die Übermittlung des Laborbefundes muss schnellstens erfolgen, damit über weitere Maßnahmen entschieden werden kann.

\section{Vorgehen}

- Unverzügliche Mitteilung des Laborbefundes (Negativ- und Positivbefund), da das Ergebnis für weitere Maßnahmen relevant ist, an den Einsender / behandelnden Arzt. Diese melden die Erkrankung gemäß $\int 6$ Abs. 1 Nr. $1 g$ IfSC an das zuständige Gesundheitsamt.

- Bei Positivbefund melden Labore an das zuständige Gesundheitsamt gemäß $\ 7$ Abs. 1 Nr. 12 IfSG.

\section{Risikobeurteilung für die Ausbreitung der Infektion}

Die Einschätzung des Ausbreitungsrisikos muss bei Auftreten von Ebolafieber-Fällen in Deutschland oder neuen Sachverhalten umgehend vom zuständigen Gesundheitsamt in Abstimmung mit Landesund ggf. Bundesbehörden erfolgen, damit geeignete und angemessene Gegenmaßnahmen getroffen 
werden können. Die Übermittlung der Risikobeurteilung und deren Aktualisierungen an das RKI erfolgt durch die oberste Landesgesundheitsbehörde.

\section{Vorgehen}

- Gesundheitsamt: Erfassung und elektronische Übermittlung der bestätigten Fälle, der begründeten Verdachtsfälle und Anzahl, Aufenthaltsort und Grad des Expositionsrisikos der Kontaktpersonen täglich über die Landesgesundheitsbehörde an das RKI.

- Auf der Basis der verfügbaren Fallzahlen, Informationen und Daten kann das RKI einen Lagebericht erstellen, der an die zuständigen Bundes- und Landesbehörden verschickt sowie ggf. bei Bedarf veröffentlicht wird.

\section{Bewältigen}

\subsection{Seuchenhygienische Maßnahmen}

7.1.1 Meldung gemäß Infektionsschutzgesetz (IfSG) und gemäß des Gesetzes zur Durchführung der Internationalen Gesundheitsvorschriften (2005) (IGV-DG)

Je früher ein Ebolafieber-Fall erkannt und an die Behörden gemeldet wird, umso eher können umfassende Schutzmaßnahmen eingeleitet werden.

\section{Vorgehen}

- Für Ärzte besteht eine unverzügliche namentliche Meldepflicht der betroffenen Person an das zuständige Gesundheitsamt bei Krankheitsverdacht oder Erkrankung oder Tod an einem virusbedingten hämorrhagischen Fieber (gemäß $\int 6$ Abs. 1 Nr. 1 g IfSG) sowie für die Labore bei direktem oder indirektem Nachweis von Ebolavirus, soweit dieser auf eine akute Infektion hinweist (gemäß $\int 7$ Abs. 1 Nr. 12 IfSG). Diese Meldungen müssen dem Gesundheitsamt spätestens 24 Stunden nach erlangter Kenntnis vorliegen und werden

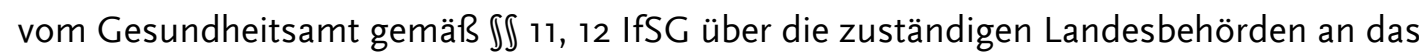
RKI übermittelt.

- Gemäß des Gesetzes zur Durchführung der Internationalen Gesundheitsvorschriften (2005) (ICV-Durchführungsgesetz - IGV-DG) besteht auch für Luftfahrzeugführer

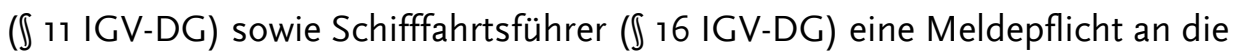
Flugverkehrskontrollstelle bzw. die zuständige Hafenaufsicht, wenn dieser erfährt, dass eine Person an Bord ist, bei der klinische Anzeichen auf das Vorliegen einer übertragbaren Krankheit hindeuten, die die öffentliche Gesundheit erheblich gefährdet, oder, dass an Bord sonstige Anzeichen für eine erhebliche Gefahr für die öffentliche Gesundheit bestehen. Von den zuständigen Stellen wird unverzüglich das zuständige Gesundheitsamt informiert.

- Wenn nach Anlage 2 der Internationalen Gesundheitsvorschriften (2005) (IGV) vom 23. Mai 2005 (BGBl. 2007 II S. 930) eine gesundheitliche Notlage von internationaler Tragweite im Sinne von Artikel ı Abs. I IGV vorliegen könnte, übermittelt das Gesundheitsamt der zuständigen Landesbehörde und diese dem RKI gemäß \ 12 IfSC unverzüglich das Auftreten des begründeten Verdachts-, Erkrankungs- oder Todesfalles, die ergriffenen Maßnahmen und sonstige Informationen, die für die Bewertung der Tatsachen und für die Verhütung und Bekämpfung der übertragbaren Krankheit von Bedeutung sind (z. B. Anzahl der erfassten Kontaktpersonen). Darüber hinaus übermittelt die zuständige 
Landesbehörde dem Robert Koch-Institut auf dessen Anforderung unverzüglich alle ihr vorliegenden Informationen, die für Mitteilungen an die Weltgesundheitsorganisation erforderlich sind. Um eine unverzügliche Bearbeitung sicherzustellen, sollte eine gleichzeitige telefonische Ankündigung der Übermittlung gemäß \ 12 IfSG an die zuständige Landesbehörde und von dort an das RKI erfolgen.

- Die Übermittlung gemäß \12 IfSG schließt neben der Infektion / Erkrankung und dem Tod auch begründete Verdachtsfälle ohne labordiagnostischen Nachweis ein. Das Gesundheitsamt informiert unverzüglich die zuständige Landesbehörde und diese unverzüglich das RKI. Das RKI bewertet die Informationen und leitet sie gemäß den IGV innerhalb von 24 Stunden nach Bewertung über die deutsche IGV-Anlaufstelle, dem gemeinsamen Melde- und Lagezentrum von Bund und Ländern (GMLZ), an die WHO und gemäß Beschluss 1082/2013/EU an die Europäische Kommission und die EUMitgliedstaaten weiter.

\subsubsection{Umgang mit symptomfreien Kontaktpersonen (Ansteckungsverdächtigen)}

Erläuterung: Im IfSC sind Ansteckungsverdächtige als Personen definiert, von denen anzunehmen ist, dass sie Krankheitserreger aufgenommen haben, ohne krank, krankheitsverdächtig oder Ausscheider zu sein. In der medizinischen Fachsprache ist hingegen der Begriff Kontaktpersonen geläufig. Dies sind It. Glossar des RKI Personen im Umfeld eines Infizierten/Erkrankten, bei der nach einem Infektionskontakt die Möglichkeit einer Kontaktinfektion (Ansteckungsverdacht i. S. des IfSG) besteht und die daher ggf. einer weiteren Beobachtung und evtl. weiterer Schutzmaßnahmen bedürfen.

Um Schutzmaßnahmen zielgerichtet umzusetzen, müssen alle Kontaktpersonen des bestätigten Ebolafieber-Falls und ggf. bereits des begründeten Verdachtsfalls ermittelt und bis zum Ende der Inkubationszeit (21 Tage) täglich aktiv durch das zuständige Gesundheitsamt nachverfolgt werden. Die Ermittlung von Kontaktpersonen zu einem Ebolafieber-Fall muss zur Verhinderung der weiteren Ausbreitung ohne Zeitverlust geschehen.

Es sind alle Personen zu ermitteln, die unmittelbaren Kontakt zum Erkrankten nach Symptombeginn hatten, und alle Personen, die mit infektiösem Material des Erkrankten in Kontakt gekommen sein könnten, u. a. Familienangehörige, medizinisches Personal, Laborpersonal, Flugpassagiere/Crew (Passagiere, die in unmittelbarer Nachbarschaft zum Indexfall gesessen haben (1 Sitz in alle Richtungen, auch über den Gang), Passagiere mit direkten Kontakt sowie den Erkrankten betreuende Crewmitglieder).

Insbesondere Körperflüssigkeiten und Körperausscheidungen (Blut, Urin, Erbrochenes, etc.) sind bei direktem Kontakt hochkontagiös. Die durch Befragung der Fälle und Recherchen ermittelten Kontaktpersonen müssen unverzüglich kontaktiert und informiert werden.

Vorgehen

- Gesundheitsamt: zeitlichen Beginn der Symptomatik klären und Ebolafieber-Erkrankten nach allen Kontaktpersonen seit Symptombeginn befragen. Kontaktpersonen ermitteln. Ggf. weitere Quellen zur Ermittlung der Kontaktpersonen heranziehen. 
- Gesundheitsamt: alle Kontaktpersonen nach dem Grad des Infektionsrisikos befragen, einteilen (siehe unten Differenzierung von Personen nach Expositionsrisiko) und erfassen (siehe Anlagen $\mathrm{H}$ und I).

- Gesundheitsamt: ermittelte Kontaktpersonen über folgende Verhaltensregeln informieren:

- Aufklärung über das Erkrankungsrisiko,

- Hinweis, sich auf Krankheitserscheinungen zu beobachten,

- Hinweis, dass sie für die maximale Inkubationszeit von 21 Tagen täglich zum Auftreten von Symptomen, insbesondere Fieber je nach Infektionsrisiko befragt werden bzw. diese selbst dokumentieren und dem Gesundheitsamt mitteilen sollen.

- Gesundheitsamt: Übermittlung von (Verdachts-)Fällen gemäß \11 und 12 IfSG, Anstellen von Ermittlungen gemäß \25 IfSG, ggf. Anordnung von Maßnahmen zum

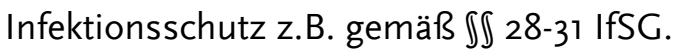

- Gesundheitsamt, Landesbehörden: Übermittlung von Informationen, die für die Bewertung der Tatsachen und für die Verhütung und Bekämpfung der übertragbaren Krankheit von Bedeutung sind, insbesondere auch bezüglich Kontaktpersonen, möglichst täglich an das RKI gemäß \ 12 IfSG.Länder, RKI: auf Anforderung der Länder kann ein Team mit aufsuchenden Epidemiologen des RKI zur Unterstützung der Landes- oder örtlichen Behörden hinzugezogen werden oder ein Koordinierungsverfahren eingeleitet werden (gemäß $\int 4$ IfSG und/oder IfSGKoordinierungs-VwV).

\section{Differenzierung von Personen nach Expositionsrisiko}

\section{Hohes Expositionsrisiko (Kategorie I)}

Person, die in den letzten 21 Tagen:

- einen ungeschützten direkten Kontakt ( $<1,5 \mathrm{~m}$ Abstand) mit einem an Ebolafieber Erkrankten in der gastrointestinalen Phase (symptomatisch, mit Erbrechen, Durchfall, Blutungen hatte (z.B. häusliche Pflege; Krankentransport; Krankenversorgung).

- einen ungeschützten direkten Kontakt mit Blut, Ausscheidungen, anderen Körperflüssigkeiten oder Geweben - einschließlich über kontaminierte Kleidung, Bettzeug, Leichentücher oder andere Gegenstände - eines an Ebolafieber Erkrankten bzw. Verstorbenen hatte (z. B. Nadelstichverletzung; Durchführung invasiver Eingriffe; ungeschützter Geschlechtsverkehr mit einem von Ebolafieber genesenen Mann, dessen Samenflüssigkeit nicht getestet wurde; Reanimation; Autopsie; Einbalsamierung; Laborarbeiten; Reinigungstätigkeiten).

Diese Punkte gelten analog für Unfälle mit infizierten Labortieren.

\section{Mittleres Expositionsrisiko (Kategorie II)}

Person, die in den letzten 21 Tagen:

- einen ungeschützten direkten Kontakt ( $<1,5 \mathrm{~m}$ Abstand) mit einem an Ebolafieber Erkrankten in der frühen Phase (symptomatisch, aber ohne Erbrechen, ohne Durchfall, 
ohne Blutungen hatte (z.B. klinische Untersuchung ohne invasive Eingriffe;

Krankentransport; Flugpassagiere +/- 1 Sitz um den Ebolafieber Erkrankten herum;

häusliche Kontakte ohne Kontakt mit Körperflüssigkeiten).

\section{Sehr geringes Expositionsrisiko (Kategorie III)}

Person, die in den letzten 21 Tagen:

- sich in räumlicher Nähe, aber ohne direkten Kontakt ( $>1,5 \mathrm{~m}$ Abstand) zu einem an Ebolafieber Erkrankten aufgehalten hat (z. B. Aufenthalt im gleichen Raum; Benutzung des gleichen öffentlichen Transportmittels).

- unter Einhaltung geeigneter Schutzmaßnahmen Kontakt hatte mit:

- Ebolafieber-Erkrankten oder Ebolafieber -Verstorbenen,

- Körperflüssigkeiten von an Ebolafieber Erkrankten oder -Verstorbenen,

- Ebolaviren, erregerhaltigem Material oder infizierten (Labor-)Tieren.

\section{Empfehlungen für den Umgang mit Personen mit Expositionsrisiko}

\section{Hohes Expositionsrisiko}

Bei diesen Personen besteht ein hohes Infektionsrisiko. Es wird daher empfohlen, dass diese Personen für 21 Tage nach dem letzten Kontakt gemäß \30 IfSG an einem geeigneten Ort, der durch das zuständige Gesundheitsamt festgelegt wird, abgesondert werden. Eine tägliche Abfrage der Symptome, insbesondere Fieber, sollte durch das zuständige Gesundheitsamt erfolgen (Anlage I).

Die Gabe einer geeigneten Postexpositionsprophylaxe sollte erwogen werden. Ihr Einsatz ist individuell zu prüfen (siehe Kapitel 7.2.5).

\section{Mittleres Expositionsrisiko}

Bei diesen Personen ist eine Beobachtung gemäß \29 IfSG angezeigt. Das Gesundheitsamt prüft darüber hinaus, ob Maßnahmen gemäß \28 IfSG zu ergreifen sind, und ordnet ggf. an, dass Kontaktpersonen für die Dauer der Inkubationszeit die eigenen Kontakte reduzieren und auf Reisen außerhalb Deutschlands verzichten.

Diese Personen sollten für 21 Tage nach dem letzten Kontakt das Auftreten von Symptomen, insbesondere Fieber, selbstständig dokumentieren (Anlage I). Eine Abfrage der Symptome sollte gemäß \29 Abs. 2 IfSG regelmäßig durch das zuständige Gesundheitsamt erfolgen (Anlage I).

Besteht der Verdacht darauf, dass eine Beobachtung nicht durchgesetzt werden kann (z.B. bei Incompliance der Kontaktperson, Unmöglichkeit der Kontaktminimierung aufgrund der räumlichen bzw. Familienverhältnisse), sollte eine Absonderung gemäß \30 IfSG erwogen werden.

\section{Sehr geringes Expositionsrisiko}

Die Arbeitsbedingungen, z. B. in der Krankenversorgung, schließen trotz gewissenhaften Umgangs mit Schutzmaßnahmen und ausreichendem Training unbemerkte Fehler in der Handhabung und damit eine Exposition nicht vollständig aus. Deshalb wird generell auch Personen, die geeignete Schutzmaßnahmen eingehalten haben, empfohlen, über einen Zeitraum von 21 Tagen nach dem letzten Kontakt ihren Gesundheitszustand selbst zu beobachten, darin eingeschlossen sind täglich morgens und abends Körpertemperatur zu messen und das Auftreten von Symptomen zu dokumentieren (Anlage J). 
Der Arbeitgeber / die entsendende Organisation sollte durch den betriebsärztlichen Dienst die Personen bei der Selbstüberwachung anleiten und begleiten. Der betriebsärztliche Dienst sollte dazu Kontakt mit dem zuständigen Gesundheitsamt aufnehmen und das Vorgehen besprechen. Rückkehrenden Personen, die im aktuellen Ausbruch in der Krankenversorgung oder Ausbruchsbekämpfung tätig waren, wird zudem generell empfohlen, sich nach Rückkehr bei ihrem zuständigen Gesundheitsamt direkt zu melden und eine gegenseitige Erreichbarkeit sicherzustellen.

Eine Beobachtung gemäß \29 IfSC bzw. eine Absonderung gemäß $\int 30$ IfSG wird bei diesen Personen nicht generell empfohlen. Das Gesundheitsamt kann im Einzelfall von dieser Empfehlung abweichen. Ein Aussetzen der Berufstätigkeit für einen Zeitraum von 21 Tagen nach dem letzten Kontakt ist aus infektiologischen Gründen nicht erforderlich, kann aber im Einzelfall aus anderen Gründen vom Arbeitgeber / von der entsendenden Organisation erwogen werden(u. a. Erholung, Vermeidung banaler Infekte und damit falscher Verdachtsfälle). Dies gilt insbesondere, wenn medizinisches Personal, welches auch in Deutschland in der unmittelbaren Krankenversorgung tätig ist, aus dem sehr belastenden Einsatz in Ausbruchsgebieten nach Deutschland zurückkehrt.

Empfohlene Maßnahmen für zurückkehrendes medizinisches und anderes Personal aus der Ebolafieber-Ausbruchsbekämpfung sind auf der Internet-Seite des RKI zu Ebola zu finden: http://www.rki.de/hilfskraefte

\section{Kein erkennbares Expositionsrisiko}

Keine Maßnahmen erforderlich.

\section{Vorgehen bei Entwicklung von Symptomen}

Entwickeln Personen mit hohem oder mäßigem Expositionsrisiko während der Inkubationszeit von 21 Tagen Symptome, die auf Ebolafieber hindeuten können, liegt bis zum Ausschluss einer Ebolavirus-Infektion ein begründeter Verdachtsfall vor (Maßnahmen siehe Kapitel 5.1).

Diese Personen sind daher im Vorfeld darauf hinzuweisen, dass sie sich, sofern sie nicht ohnehin gemäß \30 IfSG abgesondert sind, unverzüglich von anderen Menschen isolieren (Selbstisolierung vor Ort) und telefonisch beim zuständigen Gesundheitsamt Bescheid geben müssen. Die Verdachtsdiagnose sollte bei symptomatischen Kontaktpersonen sensitiv gestellt werden. Hier kann unter Umständen auch das Auftreten von subfebriler Temperatur mit einzelnen weiteren Symptomen auf den Beginn einer Ebolavirus-Infektion hinweisen.

Das Gesundheitsamt sollte sich unverzüglich an das zuständige STAKOB - Kompetenz- oder Behandlungszentrum (www.rki.de/stakob) sowie die zuständige Landesgesundheitsbehörde wenden, um das weitere Vorgehen (u. a. Krankentransport, Unterbringung, Labordiagnostik) zu besprechen und zu koordinieren.

Symptomatische Personen mit sehr geringem Risiko gelten nicht automatisch als begründeter Verdachtsfall. Bei Auftreten von Symptomen während der Inkubationszeit von 21 Tagen, die auf Ebolafieber hindeuten können, ist umgehend eine Selbstisolierung vorzunehmen und das Gesundheitsamt telefonisch zu informieren. Eine genaue Abwägung des Einzelfalles und eine ausführliche Anamnese sind bei der Risikoeinschätzung wesentlich. Dabei ist vom Gesundheitsamt zu prüfen, ob ein begründeter Verdachtsfall vorliegt und ggf. dementsprechend vorzugehen (siehe Anlage J).

\section{Hinweise}


Ist der Einsatz des Rettungsdienstes erforderlich, sollten der Erkrankte oder dessen Begleitpersonen (z. B. Familienangehörige) die Leitstelle bei der telefonischen Alarmierung auf den Status des Betroffenen als Kontaktperson zu Ebolafieber-Erkrankten hinweisen.

\subsubsection{Screening}

Theoretisch können Eingangsuntersuchungen (Entry-Screening) auf Fieber und Befragung an Grenzübergangsstellen (Points of Entry) bei Reisenden aus Epidemiegebieten durchgeführt werden. Allerdings ist der Nutzen von Entry-Screenings sehr limitiert (siehe Einschätzung des European Centre for Disease Prevention and Control (ECDC) vom 13.10.2014 (http://www.ecdc.europa.eu/en/publications/Publications/Ebola-outbreak-technicalreport-exit-entryscreening-13Oct2014.pdf)).

\subsubsection{Präventive Maßnahmen}

Zur Verhütung der Einschleppung von Ebolaviren sind die Vorschriften für importierte Tiere und Tierprodukte einzuhalten: http://www.zoll.de/DE/Unternehmen/Warenverkehr/Einfuhr-aus-einemNicht-EU-Staat/Einschraenkungen/Waren/Tiere-und-Produkte-daraus/tiere-und-produktedaraus_node.html.

Es besteht allerdings die Möglichkeit, dass infizierte tote Tiere oder deren Fleisch („Bushmeat“) illegal nach Deutschland importiert werden. Eine mögliche Gefährdung besteht dabei für das Personal der Zollbehörden und der für die Überwachung der Ein- und Durchfuhr von Erzeugnissen tierischer Herkunft zuständigen Behörden an den internationalen Umschlagsstellen (Flughäfen, Schiffshäfen). Das Risiko wird für Deutschland jedoch als sehr gering eingestuft.

\section{Weiter Informationen finden sich in Anlage K.}

\subsection{Behandlung}

\subsubsection{Krankentransport}

\section{Vorgehen}

- Der Transport von Erkrankten (bestätigte Fälle und begründete Verdachtsfälle) erfolgt in Abstimmung mit dem zuständigen Gesundheitsamt und ggf. STAKOBKompetenzzentrum / der zuständigen Landesgesundheitsbehörde.

- Die Zieleinrichtung (STAKOB-Behandlungszentrum mit Sonderisolierstation oder in Ausnahmefällen andere Krankenhäuser, siehe Kapitel 7.2.2) muss umgehend informiert werden. Die Verteilung der derzeitig sieben überregionalen STAKOB-Behandlungszentren ermöglicht Krankentransporte in eine Sonderisolierstation in Deutschland innerhalb von maximal vier bis fünf Stunden Fahrzeit.

- Der Transport erfolgt mit speziellen Infektions-Rettungswagen (IRTW). Die Anforderung des IRTW erfolgt über die Leitstelle ggf. in Abstimmung mit dem zuständigen STAKOBKompetenz- / Behandlungszentrum.

- Steht kein IRTW zur Verfügung (z. B. wegen zeitkritischer Verlegung in ein Krankenhaus), so kann der Transport in einem - möglichst - entkernten RTW erfolgen. Die Zwischenfenster zum Fahrerabteil müssen dabei geschlossen bleiben. 
- Die Verlegung des Erkrankten erfolgt im Optimalfall (z. B. bei Verlegung auf die Sonderisolierstation) in Begleitung eines Teams des STAKOB-Behandlungszentrums.

- Die Behandlung des Erkrankten während des Transports sollte nur von erfahrenem Personal durchgeführt werden,' das mit entsprechender persönlicher Schutzkleidung ausgestattet ist (siehe Kapitel 7.2.3.2).

- Zum Transport erhält der Erkrankte einen Mund-Nasen-Schutz (sofern dieser toleriert wird), eine Haube und einen Schutzkittel, um die Umgebungskontamination im RTW zu reduzieren.

- Nach dem Transport erfolgt die Wischdesinfektion aller Oberflächen mit einem Desinfektionsmittel, dessen Wirksamkeit für den Bereich $A B$ nachgewiesen ist (siehe https://www.rki.de/desinfektionsmittelliste (siehe \18 IfSG); ggf. weitere Maßnahmen nach Entscheidung des Gesundheitsamtes. Bei einem nicht entkernten RTW stellt die Dekontamination eine besondere Herausforderung dar.

- Zur Desinfektion sowie An- und Ablegen der persönlichen Schutzausrüstung siehe Kapitel 7.2.3 und Kapitel 7.2.4.

- Bestätigte Ebolafieber-Fälle und begründete Verdachtsfälle sollen nicht gleichzeitig in demselben Fahrzeug oder sequenziell ohne zwischenzeitliche Desinfektion transportiert werden. Das gleiche gilt für den Transport von mehreren begründeten Verdachtsfällen. Die Wahrscheinlichkeit für das Auftreten von mehr als einem bestätigten Fall oder mehreren begründeten Verdachtsfällen von Ebolafieber, die gleichzeitig vom selben Ort abtransportiert werden müssen, ist allerdings äußerst gering.

- Da Helikopter ohne Gefährdung der Bordelektronik derzeit nicht zu desinfizieren sind, und der Zugang zum Erkrankten sehr eingeschränkt ist, wird ein Krankentransport in diesen Verkehrsmitteln, sofern vermeidbar, nicht empfohlen.

\subsubsection{Anforderungen an Behandlungseinrichtungen}

Die Behandlung begründeter Verdachtsfälle und bereits bestätigter Fälle sollte primär in den STAKOB-Behandlungszentren mit Sonderisolierstationen erfolgen. Hier sind die Anforderungen der Technischen Regel für Biologische Arbeitsstoffe (TRBA) 250 (siehe Anlage E) zu erfüllen.

Müssen begründete Verdachtsfälle bzw. in Ausnahmefällen bereits bestätigte Fälle (z. B. wegen Nichtverlegbarkeit des Erkrankten oder sonstiger nicht vorhersehbarer Umstände) außerhalb von Sonderisolierstationen betreut werden, so hat dies unter räumlichen Isolationsbedingungen zu erfolgen. Hier sind die Anforderungen des ABAS-Beschlusses 610 (siehe Anlage F) zu beachten.

Die Entscheidung, welche Einrichtungen für eine vorübergehende Behandlung nicht verlegbarer Ebolafieber-Erkrankte in Betracht kommen, erfolgt durch das zuständige Gesundheitsamt bzw. auf Länderebene.

\subsubsection{Schutzmaßnahmen für das Personal}

\section{Grundsätzliche Anmerkungen}

Die Versorgung eines Erkrankten mit Ebolafieber (bestätigter Fall und begründeter Verdachtsfall) erfolgt ausschließlich durch eingewiesenes und geschultes Personal. Sie hat unter dem

\footnotetext{
' Siehe auch TRBA 200: Anforderung an die Fachkunde nach Biostoffverordnung.
} 
Gesichtspunkt der Kontaktminimierung zu erfolgen. Invasive Eingriffe insbesondere außerhalb der Sonderisolierstationen sind auf das Notwendigste zu beschränken. Grundlegende Schutzmaßnahmen, wie z. B. Einhaltung aller Hygienemaßnahmen und sichere Entsorgung von festen und flüssigen Abfällen, gelten grundsätzlich bei der Behandlung aller Erkrankten.

Sollte für die Probenahme und evtl. Versorgung der Erkrankten der Einsatz spitzer und scharfer medizinischer Instrumente notwendig sein, sind Arbeitsgeräte mit Sicherheitsmechanismen (Sicherheitsgeräte, vorzugsweise mit selbstauslösendem Sicherheitsmechanismus) einzusetzen und diese in einen geeigneten Abwurfbehälter (,sharps container") abzuwerfen (siehe Anlage $\mathrm{E}$ Ziffer 4.2.5 Absatz 3 ff.).

\section{Allgemeine Hinweise}

Kontaktminimierung, allgemeine Hygienemaßnahmen einhalten.

\section{Spezielle Hinweise}

Bei engem Kontakt (z. B. körperliche Untersuchung, medizinische Behandlung, Krankentransport) zu einem begründeten Verdachtsfall oder bestätigten Ebolafieber-Fall müssen die folgenden Maßnahmen zum Arbeitsschutz beachtet werden. Die Grundlage für die Empfehlungen ist die TRBA 250. Die im Folgenden beschriebenen Schutzmaßnahmen sind mit dem Koordinierungskreis und dem Ad Hoc-Arbeitskreis Ebola des Ausschusses für Biologische Arbeitsstoffe (ABAS) abgestimmt.

Situationsbedingt werden im Folgenden zwei Konzepte unterschieden:

1. Krankenversorgung in Sonderisolierstationen,

2. Krankenversorgung außerhalb von Sonderisolierstationen.

\subsubsection{Krankenversorgung in Sonderisolierstationen}

Schutzmaßnahmen wie in Anhang 1 Teil 1 der TRBA 250 festgelegt (siehe Anlage E).

\subsubsection{Krankenversorgung außerhalb von Sonderisolierstationen}

Schutzmaßnahmen wie in ABAS-Beschluss 610 empfohlen (siehe Anlage F).

Wenn ein begründeter Verdachtsfall festgestellt wird, verbleibt der Erkrankte zunächst vor Ort. Es wird davon ausgegangen, dass die Verweildauer des Erkrankten hier kurz ist und nur die absolut notwendigen Tätigkeiten am Erkrankten ausgeführt werden, bevor er in eine Sonderisolierstation verlegt wird.

Für die Erstversorgung der Erkrankten sollte in Krankenhäusern, insbesondere in der Notaufnahme, sowie in Arztpraxen, bei Rettungsdiensten und bei Gesundheitsämtern persönliche Schutzausrüstung in ausreichender Menge verfügbar sein.

Sobald wie möglich sollte ein begründeter Verdachtsfall oder bestätigter Ebolafieber-Fall zur weiteren Behandlung auf eine Sonderisolierstation gebracht werden. Details hierzu sind länderspezifisch unterschiedlich geregelt.

Müssen bestätigte Ebolafieber-Fälle in Ausnahmefällen außerhalb von Sonderisolierstationen betreut werden (z. B. wenn der Erkrankte aufgrund seines Gesundheitszustandes nicht verlegt werden kann), so wird in Bezug auf Atemschutz das Tragen von gebläseunterstütztem Atemschutz $\mathrm{TH}{ }_{3} \mathrm{P}$ (bei Einsatz von Desinfektionsmitteln zusätzlich mit dem hierfür geeigneten Gasfilter A, B, E und/oder K) 
empfohlen. Mindestens ist als Atemschutz eine FFP3-Halbmaske mit den im ABAS-Beschluss 610 beschriebenen Eigenschaften zu verwenden.

Eine Beschreibung der weiteren Komponenten des PSA (Körper-, Augen-, Hand- und Fußschutz, weiteren PSA-Optionen sowie Empfehlungen für die Abtrennung eines Isolierbereichs sind im ABASBeschluss $610 \mathrm{im} \mathrm{Kapitel} \mathrm{4.5.12} \mathrm{aufgeführt} \mathrm{(siehe} \mathrm{Anlage} \mathrm{F).}$

\subsubsection{An- und Ablegen der persönlichen Schutzausrüstung}

Ein Infektionsschutz durch die persönliche Schutzausrüstung (PSA) entsteht nur, wenn diese korrekt angelegt, getragen, dekontaminiert, ausgezogen und entsorgt wird. Aus diesem Grund sind regelmäßige Übungen zum Umgang mit der PSA notwendig, um im Ernstfall Fehler und hieraus folgende Infektionen zu vermeiden. Detaillierte Hinweise zum An- und Ablegen der PSA finden sich in ABAS-Beschluss 610 (siehe Anlage F).

\section{Vorgehen}

- Vor dem Ablegen der Schutzkleidung muss eine Desinfektion der Schutzkleidung erfolgen.

- Bei bestätigten Fällen von Ebolafieber sollte eine Ganzkörper-Dekontamination durchgeführt werden. Das An- und Ablegen der Schutzkleidung sowie Dekontamination erfolgen in diesem Fall immer mit Hilfe einer weiteren Person (sog. „Buddy-System“).

- Bei begründeten Verdachtsfällen kann nach sorgsamer Risikobewertung im Einzelfall von einer Ganzkörper-Dekontamination abgesehen werden. Die Schutzkleidung sollte in diesem Fall vor dem Ablegen mindestens im Bereich potentiell sichtbarer Kontamination mit einem Schwamm und einem Desinfektionsmittel wischdesinfiziert werden.

Dekontamination (Ganzkörper-Dekontamination bzw. Dekontamination gezielter Stellen, siehe Anlage L)

- Anwendung eines Desinfektionsmittels mit dem Wirkungsbereich begrenzt viruzid (bzw. viruzid) unter Einhaltung der vorgegebenen Einwirkzeiten.

- Das Desinfektionsmittel sollte mit ausreichend saugfähigen Tüchern bzw. in einer Wanne aufgefangen und entsorgt werden (siehe Kapitel 7.2.4.8).

- Bezüglich der Desinfektion der persönlichen Schutzausrüstung wird auch auf die speziellen Angaben im Anhang zur Liste der vom RKI geprüften und anerkannten Desinfektionsmittel und -verfahren „Desinfektion von speziellen Oberflächen“ verwiesen: https://www.rki.de/desinfektionsmittelliste

- Die Schutzkleidung muss nach erfolgter Desinfektion so ausgezogen und abgelegt werden, dass die Außenseite nicht mit der Kleidung oder Haut in Berührung kommt („Ausschälen“); d. h. ein Schutzanzug ist so ausziehen, dass die Innenseite nach außen kommt.

- Die Handschuhe müssen nach dem Berühren der Außenseite des Anzugs oder der Maske abgelegt, die Hände desinfiziert und gewaschen, sowie die Handschuhe ersetzt werden.

- Die Schutzkleidung muss beim Verlassen des kontaminierten Raumes / Bereichs ausgezogen werden und im Vorraum in einem gekennzeichneten Autoklav-Beutel gemäß EAK 180103* oder nach (thermischer) Abfalldesinfektion zurückgelassen und in geeigneter Verpackung als infektiöser Abfall der Abfallentsorgung zugeführt werden (siehe Kapitel 7.2.4.6). 
- Vor dem Ausziehen sollten die Handschuhe mit einem Händedesinfektionsmittel mit mindestens begrenzt viruzider Wirksamkeit desinfiziert werden.

- Die Hände sollten nach dem Ablegen der Handschuhe mit einem Händedesinfektionsmittel mit mindestens begrenzt viruzider Wirksamkeit desinfiziert werden.

- Alle potentiell kontaminierten Oberflächen, z. B. im Schleusenbereich, sind mittels sorgfältiger Wischdesinfektion (Wirkungsbereich begrenzt viruzid bzw. viruzid) zu desinfizieren.

\subsubsection{Erforderliche Desinfektionsmaßnahmen / Abfallentsorgung}

Vorgehen (siehe Anlage L)

Das Vorgehen in den Sonderisolierstationen ist durch die TRBA 250 (siehe Anlage E) und außerhalb von Sonderisolierstationen durch den ABAS-Beschluss 610 (siehe Anlage F) sowie weitere Vorschriften z. B. zum Infektionsschutz geregelt.

- Alle Maßnahmen müssen in Abstimmung mit dem zuständigen Gesundheitsamt und ggf. STAKOB-Kompetenz- und Behandlungszentrum erfolgen.

- Die Umgebung, in der sich der potenziell kontagiöse Erkrankte aufgehalten hat (z. B. Wohnung, Auto, Arztpraxis) und in der es einen direkten Kontakt mit Körperflüssigkeiten bzw. mit der Haut des Erkrankten gegeben hat oder gegeben haben könnte, sollte bis zum Erhalt der gesicherten Diagnose abgesperrt und überwacht werden.

- Ist dies nicht möglich bzw. handelt es sich um einen bestätigten Ebolafieber-Fall, erfolgt die Dekontamination durch die nachfolgend beschriebenen Desinfektionsmaßnahmen.

- Dabei ist der Zugang zu dem jeweiligen Bereich zu sperren und die Anzahl der Personen innerhalb des Bereiches auf das unmittelbar erforderliche Maß zu beschränken.

- Geeignete Möglichkeiten zur gegenseitigen Dekontamination und zum Wechsel der PSA sind am Zugang des Bereiches einzurichten.

- Die Wischdesinfektion der oben aufgeführten kontaminierten Flächen und der PSA stellt das Mittel der ersten Wahl dar. Nur in Ausnahmefällen, sofern durch eine Flächendesinfektion nicht alle kontaminierten Bereiche desinfiziert werden können, kommt eine Raumdesinfektion mittels Verdampfung von Formaldehyd oder Wasserstoffperoxid zusätzlich zur Flächendesinfektion in Betracht.

- Kontaminierte Gegenstände, die nicht sicher desinfiziert werden können, sind gemeinsam mit der benutzen und dekontaminierten PSA nach Abfallschlüssel 180103* zu entsorgen.

- Desinfektionsmittel mit nachgewiesener, mindestens begrenzt viruzider Wirksamkeit (wirksam gegen behüllte Viren; siehe dazu „Prüfung und Deklaration der Wirksamkeit von Desinfektionsmitteln gegen Viren") sind zur Desinfektion bei Kontamination mit Ebolaviren ausreichend. Viruzide Desinfektionsmittel, d. h. Mittel, die zusätzlich auch gegen unbehüllte Viren wirksam sind, können ebenfalls angewendet werden.

\section{- $\quad$ https://www.rki.de/desinfektionsmittelliste}

- Desinfektionsmittel mit dem Wirkungsbereich $A B$ aus der Liste der vom RKI geprüften und anerkannten Desinfektionsmittel und -verfahren (RKI-Liste) oder der DesinfektionsmittelListe des Verbundes für Angewandte Hygiene (VAH-Liste) mit dem Wirkungsbereich begrenzt viruzid (bzw. viruzid plus oder viruzid) sind hierfür geeignet. Wenn das 
Gesundheitsamt eine Desinfektion behördlich anordnet, so ist die RKI-Liste heran zu ziehen.

- https://www.rki.de/desinfektionsmittelliste

- $\quad$ http://www.vah-online.de/index.php?page=desinfektionsmittel-liste-2

- Bezüglich der Desinfektion der persönlichen Schutzausrüstung wird auch auf die speziellen Angaben im Anhang zur Liste der vom RKI geprüften und anerkannten Desinfektionsmittel und -verfahren „Desinfektion von speziellen Oberflächen“ verwiesen.

- https://www.rki.de/desinfektionsmittelliste

- Das zur Desinfektion eingesetzte Personal muss entsprechend der situationsbedingten Gefährdungsbeurteilung persönliche Schutzausrüstung tragen. Bei einem hohen Gefährdungspotential, z. B. bei massiver Verschmutzung mit Körperflüssigkeiten oder bei bestätigter Diagnose sollte die in Kapitel 7.2.3.2 beschriebene Schutzkleidung getragen werden. Das Personal muss zum An- und Ablegen der persönlichen Schutzausrüstung unterwiesen und trainiert sein.

\subsubsection{Händedesinfektion, Hautdesinfektion, Schleimhautdesinfektion}

\section{Vorgehen (siehe Anlage L)}

- Während der Versorgung eines begründeten Verdachtsfalls und eines bestätigten Ebolafieber-Falls muss Schutzkleidung inkl. Schutzhandschuhen getragen werden. Nach dem Ablegen der Handschuhe oder nach einer Kontamination sind die Hände mit einem Händedesinfektionsmittel mit nachgewiesener begrenzt viruzider Wirksamkeit zu desinfizieren (ebenso möglich sind viruzide Desinfektionsmittel). Diese Mittel können aus pragmatischen Gründen auch zur Desinfektion anderer akzidentell kontaminierter Hautareale angewendet werden.

- Informationen dazu unter der RKI-Liste, Abschnitt 2.3, der VAH-Liste und der „Empfehlung der Kommission für Krankenhaushygiene und Infektionsprävention beim Robert KochInstitut - Händehygiene“.

- https://www.rki.de/desinfektionsmittelliste

- http://www.vah-online.de/index.php?page=desinfektionsmittel-liste-2

- http://www.rki.de/DE/Content/Infekt/Krankenhaushygiene/Kommission/Downloads/H aendehyg_Rili.pdf

- Zur Schleimhautdesinfektion können Octenidindihydrochlorid/Phenoxyethanol- oder Chlorhexidin-haltige Arzneimittel oder Povidon-lod-Komplexe (7,5\%) entsprechend ihrer zugelassenen Anwendungsgebiete zur Anwendung kommen, z. B. Octenisept, Skinsept mucosa, Braunol. Für die Anwendung am Auge ist $5 \%$ Povidon-lod-Komplex geeignet.

\subsubsection{Desinfektion von Flächen}

Vorgehen (siehe Anlage L)

- Alle Oberflächen, die mit Körperflüssigkeiten in direkten Kontakt gekommen sind bzw. sein könnten, sowie Hautkontaktflächen, sind mittels sorgfältiger Wischdesinfektion zu desinfizieren. Informationen zu dazu geeigneten Mitteln unter der RKI-Liste, Abschnitt 2.2 und der VAH-Liste (siehe oben). 
- Zur Durchführung der Flächendesinfektion wird auf die Empfehlung der Kommission für Krankenhaushygiene und Infektionsprävention (KRINKO) zu „Anforderungen an die Hygiene bei der Reinigung und Desinfektion von Flächen“ verwiesen.

- https://www.rki.de/DE/Content/Infekt/Krankenhaushygiene/Kommission/Downloads/F laeche_Rili.pd??_blob=publicationFile

- Sichtbare Verunreinigungen (z. B. mit Blut, Erbrochenem) werden unter Verwendung der vorgeschriebenen Schutzkleidung mit einem mit dem Flächendesinfektionsmittel getränkten Einmaltuch aufgenommen und als infektiöser Abfall gemäß Abfallschlüssel 180103* entsorgt. An diesen Stellen sollte vor der Desinfektion der Gesamtfläche eine zweimalige lokale Wischdesinfektion erfolgen (siehe Dekontamination / Desinfektion in BLagen:

https://www.rki.de/DE/Content/Infekt/Biosicherheit/Dekontamination/Dekontamination node.html).

- Unmittelbar nach Entlassung bzw. Tod eines Erkrankten ist eine Schlussdesinfektion als desinfizierende Flächenreinigung sämtlicher zugänglicher Flächen und Gegenstände (inkl. Bettengestelle und Matratzen bei Verwendung von Schutzbezügen, sonst thermische Desinfektion) durchzuführen.

\subsubsection{Desinfektion von Medizinprodukten (Instrumente und Geräte)}

Vorgehen (siehe Anlage L)

- Alle Instrumente bzw. Geräte, die mit Körperflüssigkeiten von an Ebolafieber Erkrankten in direkten Kontakt gekommen sind bzw. sein könnten, sind initial gesondert zu desinfizieren. Je nach Aufbereitungsvorschrift für das jeweilige Instrument bzw. Gerät muss dazu eine Flächendesinfektion (durch Wischen) oder eine Instrumentendesinfektion (durch Eintauchen) durchgeführt werden. Kontaminierte Gegenstände, die nicht sicher desinfiziert werden können, sind nach Abfallschlüssel 180103* zu entsorgen.

- Zur Durchführung der Aufbereitung von Medizinprodukten wird auf die Empfehlung der Kommission für Krankenhaushygiene und Infektionsprävention beim RKI und des Bundesinstitutes für Arzneimittel und Medizinprodukte zu den „Anforderungen an die Hygiene bei der Aufbereitung von Medizinprodukten“ verwiesen.

- http://www.rki.de/DE/Content/Infekt/Krankenhaushygiene/Aufb_MedProd/Aufb_MedP rod_node.html

- Das Vorgehen bei der Desinfektion großer Geräte sollte jeweils individuell festgelegt werden. Es hängt vom wahrscheinlichen Ausmaß der Kontamination ab und sollte gemäß den üblichen Desinfektionsvorschriften und Herstellerangaben erfolgen. Es kommt ergänzend eine Begasung mit Formaldehyd oder eine Bedampfung mit Wasserstoffperoxid in Betracht. Gegebenenfalls sind spezielle Vorkehrungen vorzusehen für Schläuche und Flüssigsysteme, die a) entleert und b) desinfiziert werden. Sollte vor der gesamten Gerätedesinfektion ein Transport erfolgen, z. B. in den Autoklavenraum, muss das Flüssigsystem vorher entleert und desinfiziert und dann nochmals entleert werden.

- Individuelles Vorgehen ist ebenfalls bei Analysengeräten (z. B. in vitro-Diagnostik) notwendig. Eine Wisch- oder Sprühdesinfektion reicht in der Regel NICHT aus, da Flüssigkeiten in nicht erreichbare Stellen (Ecken, Spalten, Fugen) am Gerät gelangen 
können. Ein Begasungsverfahren ist geeigneter und ist für den jeweiligen Gerätetyp zu validieren.

- Für Instrumente und Automaten, die für die Primärdiagnostik und Probenvorbereitung unter Bedingungen der Schutzstufe 3 verwendet werden, gelten die Bedingungen, die im ersten Punkt dieses Abschnitts genannt werden. Patientenproben, die nach der ordnungsgemäßen Behandlung mit Virus-Lysepuffer (AVL-Puffer+EtOH) z. B. einer PCRAnalytik zugeführt werden und anschließend kontrolliert und in neuen Probengefäßen in Schutzstufe 2 transferiert werden, stellen für die Analysengeräte (PCR Analyser) keine Kontaminationsgefahr dar. Diese sind gemäß den üblichen Desinfektionsvorschriften und Herstellerangaben zu behandeln.

\subsubsection{Raumdesinfektion}

\section{Vorgehen (siehe Anlage L)}

- In Ausnahmefällen, sofern durch eine Flächendesinfektion nicht alle kontaminierten Bereiche desinfiziert werden können, kommt eine Raumdesinfektion mittels Verdampfung von Formaldehyd oder Wasserstoffperoxid (RKI-Liste, Abschnitt 3.3) zusätzlich zur Flächendesinfektion in Betracht.

\subsubsection{Wäschedesinfektion}

\section{Vorgehen (siehe Anlage L)}

- Bei der Versorgung von begründeten Verdachtsfällen und bestätigten Ebolafieber-Fällen sollte Einmalwäsche verwendet werden, die anschließend der Abfallentsorgung zuzuführen ist. Potentiell kontaminierte Kleidungstücke und potentiell kontaminierte sonstige Wäsche muss in geeigneter Verpackung der Abfallentsorgung zugeführt werden.

\subsubsection{Abfallentsorgung ${ }^{2}$}

Informationsmaterial zum Abfallmanagement findet sich unter www.rki.de/ebola-desinfektion.

\section{Maßnahmen und Empfehlungen für die Einrichtungen des Gesundheitsdienstes}

- Wenn möglich, ist die Inaktivierung der entstehenden Abfälle, welche bei der Versorgung eines begründeten Verdachts- oder bestätigten Ebolafieber-Falls anfallen, nach Biostoffverordnung (BioStoffV) in unmittelbarer Nähe des Anfallortes der Abfälle durchzuführen.

- Die Ausrüstung von medizinischen Einrichtungen mit entsprechenden Autoklaven ist derzeit nur in Einzelfällen gegeben. Bei geplanten Neuausstattungen oder Nachrüstungen müssen Desinfektionsanlagen bestimmte Anforderungen erfüllen, die in der Bund/LänderArbeitsgemeinschaft Abfall (LAGA)-Vollzugshilfe aufgeführt sind (siehe Anlage M). Dazu heißt es: „Die Desinfektionsanlagen sind entsprechend den zur Desinfektion von Abfällen vorgegebenen Betriebsparametern zu betreiben. Diese Betriebsweise ist zu dokumentieren. Der Betrieb ist nur zulässig, wenn der Betreiber den Nachweis vorlegen

\footnotetext{
${ }^{2}$ Ursprünglich erarbeitet von einem Arbeitskreis mit Sachverständigen aus RKI, Bundesanstalt für Materialforschung und -prüfung (BAM), Umweltbundesamt (UBA), Bundesanstalt für Arbeitsschutz und Arbeitsmedizin (BAuA), DFV, Verband der Chemischen Industrie e.V. (VCI) und weiteren Experten im November 2014.
} 
kann, dass die Anlage baulich und funktionell den Anforderungen der DIN 58949 oder anderen, bei der Aufnahme in die RKI-Liste gemäß \ 18 IfSG festgelegten Spezifikationen entspricht und gemäß dieser Vorschriften geprüft und betrieben wird.“

- Weitere Informationen zu Desinfektionsverfahren finden sich in der Liste der vom RKI geprüften und anerkannten Desinfektionsmittel und -verfahren unter Ziffer 3.4.

- https://www.rki.de/desinfektionsmittelliste

- In Sonderisolierstationen sollten vorzugsweise Durchreicheautoklaven für die Vorortbehandlung von Abfällen aus der Krankenversorgung vorhanden sein (siehe auch Anlage E, Anhang 1, Ziffer 1.2.6).

- Gegebenenfalls müssen beim Einsatz ortsfester Autoklaven Regelungen zum innerbetrieblichen Transport der infektiösen Abfälle berücksichtigt werden.

- Eine Alternative zu ortsfesten Autoklaven könnten auf Fahrzeuge installierte mobile Desinfektionsanlagen sein, die die entsprechenden Vorgaben erfüllen. Bereits seit längerer Zeit existieren dafür Konzepte, die allerdings von potenziellen Anbietern hinsichtlich der Machbarkeit geprüft und ggf. umgesetzt werden müssten. Mobile Desinfektionsanlagen könnten z. B. auf Flughäfen und in Behandlungseinrichtungen, die nur selten mit entsprechenden Entsorgungsanforderungen konfrontiert sind, eingesetzt werden.

- Falls die Inaktivierung des infektiösen Abfalls vor Ort aus technischen oder logistischen Gründen nicht möglich ist, muss der Abfall außerhalb des Anfallortes sachgerecht beseitigt werden. In diesem Fall ist der Abfall in einer Sonderabfallverbrennungsanlage (SAV), die für den Abfall mit Abfallschlüssel 180103* genehmigt ist, der sachgerechten Verbrennung zuzuführen.

- Für den Transport zur SAV muss entsprechend dem ADR der Abfall grundsätzlich nach der Verpackungsvorschrift P620 mit der Kennzeichnung UN 2814 verpackt werden. Für kleine Materialmengen sind von der BAM entsprechende Behälter zugelassen.

- http://www.tes.bam.de/de/service/aktuelles/Ebola_Verpackungen.pdf

- Es hat sich allerdings gezeigt, dass für größere Mengen von infektiösem Abfall derzeit in der Praxis keine ausreichend großen Behälter, die in vollem Umfang der Verpackungsvorschrift P620 entsprechen, in Deutschland und anderen Ländern der Europäischen Union zur Verfügung stehen. Deshalb unterzeichnete Deutschland am 27.11.2014 die multilaterale Vereinbarung M281 von Mitgliedsstaaten der Europäischen Union. Diese Vereinbarung war zeitlich begrenzt bis zum 31.12.2016 und stellt eine Ausnahmeregelung für die Verpackung zum Transport von Abfall, der mit Ebolaviren kontaminiert sein kann, dar. Mittlerweile ist diese Vereinbarung durch die multilaterale Vereinbarung M315 (siehe Anlage N) abgelöst worden. Die Sicherheit wird wie in der Verpackungsvorschrift P620 durch die Anwendung einer hochwertigen Dreifachverpackung gewährleistet. Grundsätzlich besteht diese Verpackung aus:

- Primärbehälter: ${ }_{1} \mathrm{H}_{2} / \mathrm{Y}$ Kunststoffdeckelfass, das den Erfordernissen nach 4.1.1 und 4.1.3 ADR entspricht, Innenvolumen bis 60 Liter für diesen Zweck verfügbar, Öffnungsdurchmesser ca. $400 \mathrm{~mm}$, flüssigkeitsdicht, Deckel vorzugsweise mit Klebedichtung, Einwegverschluß (nicht wieder zu öffnen),

- Sekundärverpackung: PE Beutel mit einer Materialdicke von vorzugsweise $100 \mu \mathrm{m}$, mindestens jedoch $75 \mu \mathrm{m}$, 
- Außenverpackung: 1 $\mathrm{H}_{2} / \mathrm{X}$ Kunststoffdeckelfass mit Spannringverschluss; Außenmaße ca. Durchmesser $500 \mathrm{~mm}$, Höhe $800 \mathrm{~mm}$.

Eine Musteranleitung findet sich in Anlage 0.

- Gemäß Gefahrgutbeauftragtenverordnung (GBV) muss der Versender (das Krankenhaus oder die medizinische Einrichtung) vor der ersten Beförderung einen Gefahrgutbeauftragten bestellt haben. Das kann eine nachweislich geschulte und geprüfte interne Kraft, als auch ein externer Gefahrgutbeauftragter mit gültigem Schulungsnachweis als Honorarkraft sein. Der Gefahrgutbeauftragte muss alle beschriebenen Verfahren anweisen, die Beteiligten unterweisen und letztlich jeden Vorgang gewissenhaft überwachen.

- Der Versender des infektiösen Abfalls hat zudem für den Transporteur ein Beförderungspapier zu erstellen. Ein Muster dafür findet sich in Anlage $P$.

- In medizinischen Behandlungseinrichtungen, die Ebolafieber-Erkrankte versorgen, muss für das Management von infektiösem Abfall, der mit hoher Sicherheit Erreger von virusbedingten hämorrhagischen Fiebern (wie Ebolavirus) enthält, ein Sicherungsplan erstellt werden. Ein Muster dafür findet sich in Anlage $Q$.

\section{Maßnahmen und Empfehlungen für den Transport der infektiösen Abfälle}

- Der Transport von ansteckungsgefährlichen Stoffen ist im Wesentlichen durch das ADR geregelt. Der Transport von nicht inaktivierten Abfällen bei bestätigtem Verdacht auf hämorrhagisches Fieber (wie Ebolafieber) erfolgt als Klasse 6.2, Kategorie A unter der UNNummer 2814. Zusätzliche Sicherheitsanforderungen im Zusammenhang mit Ebolavirushaltigem Abfall finden sich in der o.g. Ausnahmeregelung M315.

- Die Anwendung der Multilateralen Vereinbarung M315 ermöglicht die Beförderung von Abfällen, die mit Ebolaviren kontaminiert sind oder kontaminiert sein könnten erfordert jedoch einen zusätzlichen Vermerk im Beförderungspapier „Beförderung vereinbart nach Abschnitt 1.5.1 ADR (M315)“.

- Entsprechende Serviceunternehmen, die den sachgerechten und sicheren Transport der infektiösen Abfälle übernehmen können, stehen in Deutschland zur Verfügung und sind in der Regel bereits Bestandteil des Abfallmanagements in der klinischen Praxis. Bereits vor dem Transport der Abfälle müssen mit einer geeigneten Sonderabfallverbrennungsanlage entsprechende Vereinbarungen zur Annahme getroffen werden.

\section{Maßnahmen und Empfehlungen für die Verbrennung der infektiösen Abfälle}

- In den SAV, die für den Abfall mit Abfallschlüssel 180103* genehmigt sind, ist davon auszugehen, dass die baulichen und technischen Voraussetzungen für die fachgerechte Verbrennung des infektiösen Abfalls gewährleistet sind. Als zusätzliche organisatorische Maßnahme ist eine eindeutige Arbeitsanweisung in den SAV zur zügigen und sachgerechten Abfertigung des Sonderabfalls mit der Identifikation UN 2814 zu erstellen. Dabei ist zu berücksichtigen:

- Dass vom Versender sichere und für den Anwendungszweck zugelassene Mehrfachverpackungen verwendet werden, die gegen mechanische Belastungen eine hohe Widerstandsfähigkeit aufweisen.

- Dass eine zeitnahe Verbrennung dieser Gebinde erfolgt. 
- Dass nur Fassaufzüge oder vergleichbare Aufgabeeinrichtungen verwendet werden, die die Abfallbehältnisse nicht beschädigen.

- Dass bei dem unwahrscheinlichen Fall von Bruch oder Leckage der Abfallbehälter oder sonstiger Störungen der betroffene Bereich abgesperrt werden muss, und die weiteren Maßnahmen mit dem zuständigen Gesundheitsamt festgelegt werden müssen.

- Der Abfallschlüssel 180103* beinhaltet auch Abfall, der mit Krankheitserregern von virusbedingtem hämorrhagischen Fieber (eingeschlossen Ebolavirus) kontaminiert sein kann. Aus bestehenden Verträgen oder Andienungsverpflichtungen zu diesem Abfallschlüssel leitet sich für den Betreiber der SAV eine Entsorgungsverpflichtung ab. Die genaue Beschreibung des Abfallschlüssels regelt die LAGA-Vollzugshilfe M18, die in der Mehrzahl der Bundesländer per Erlass eingeführt ist (siehe Anlage M).

- Für die Verbrennung von Abfällen aus Gesundheitseinrichtungen, die mit Erregern der Risikogruppe 4 (wie Ebolavirus) kontaminiert sind, sind in SAV zusätzlich zu den oben genannten Vorgaben keine weiteren Sonderregelungen notwendig.

\subsubsection{Abwasserentsorgung}

Weitere Informationen finden sich in Anlage $L$.

\section{Vorgehen bei begründeten Verdachtsfällen}

Da in der Anfangsphase der Erkrankung nur geringe Virusausscheidung erfolgt und außerdem von einem hohen Verdünnungseffekt auszugehen ist, kann Abwasser, inklusive Stuhl und Urin, welches bei der initialen Versorgung eines begründeten Ebolafieber-Verdachtsfalls anfällt, außerhalb von Sonderisolierstationen über eine separat genutzte Toilette in das normale Abwassersystem entsorgt werden.

Müssen wegen eingeschränkter Mobilität des Erkrankten ein Toilettenstuhl oder ein Steckbecken verwendet werden, so sollte dies bevorzugt mit Einweggeschirr geschehen. Der Inhalt kann - unter Verwendung adäquater persönlicher Schutzausrüstung - über die separat genutzte (personengebundene) Toilette entsorgt werden. Steht kein Einweggeschirr zur Verfügung, so ist das verwendete Material nach der Entleerung über die Toilette unmittelbar im Raum in einem geeigneten Behälter mit einem Desinfektionsmittel mit dem Wirkungsbereich $A B$ aus der RKI-Liste zu desinfizieren. Die kontaminierten Sanitäreinrichtungenen sind einer sorgfältigen Desinfektion zu unterziehen.

\section{Vorgehen bei bestätigten Fällen}

\section{Vorübergehende Isolierung außerhalb von Sonderisolierstationen}

Abwasser, inklusive Stuhl und Urin, welches bei der Versorgung eines bestätigten Ebolafieber-Falls anfällt, ist in geeigneten Behältern aufzufangen und mit einem für die Desinfektion von Ausscheidungen geeigneten Desinfektionsmittel mit mindestens begrenzt viruzider Wirkung in sicher wirksamer Konzentration (vorrangig Kalkmilch entsprechend den Angaben der RKIDesinfektionsmittel-Liste; Wirkungsbereich AB (RKI-Liste, Abschnitt 2.2)) zu versetzen und anschließend (nach Ende der entsprechenden Einwirkzeit) über einen separat genutzten Fäkalienabfluss zu entsorgen, wenn eine thermische Inaktivierung nicht möglich ist. 
Nicht aufgefangener Stuhl sowie andere Körperflüssigkeiten müssen mit einem mit Desinfektionsmittel getränkten saugfähigen Tuch bzw. Zellstoff zunächst abgedeckt und anschließend sicher aufgenommen werden.

Alternativ können die Ausscheidungen in einem geeigneten Gefäß, das saugfähiges Material (z. B. Inkontinenzmaterial) enthält, aufgefangen werden. Die somit gebundenen Flüssigkeiten werden anschließend als infektiöser Abfall (AS 180103*) entsorgt (siehe oben Abfallentsorgung).

Wurden Sanitäreinrichtungen von dem Erkrankten bereits benutzt oder lassen die Umstände keine andere Möglichkeit zu, sind die kontaminierten Sanitäreinrichtungenen einer sorgfältigen Desinfektion zu unterziehen.

\section{Sonderisolierstationen}

Die Abwasserentsorgung in den Sonderisolierstationen erfolgt nach einer geeigneten Inaktivierung und ist mit der TRBA 250 Anhang 1 geregelt.

\subsubsection{Entsorgung des verwendeten Desinfektionsmittels}

Vorgehen

- Wurde das verwendete Desinfektionsmittel durch die Anwendung nicht zusätzlich verdünnt, kann nach einer anschließenden Standzeit, die mindestens der Angabe der Einwirkzeit für die (begrenzt) viruzide Wirksamkeit entspricht, davon ausgegangen werden, dass keine relevanten Erregerkonzentrationen mehr vorhanden sind.

- Da aber partikuläre Bestandteile (Umweltschmutz, organisches Material, insbesondere Patientenausscheidungen etc.) in der desinfektionsmittelhaltigen Flüssigkeit nach der Dekontamination die Wirksamkeit des Desinfektionsmittels beeinträchtigen können, sollten solche Rückstände, sofern der Eintrag nicht vermieden werden kann, unter Beachtung der Schutzmaßnahmen wie Patienten-Ausscheidungen entsorgt werden.

- Die Entsorgung des genutzten Desinfektionsmittels erfolgt grundsätzlich gemäß örtlicher behördlicher Vorschriften entsprechend der Angaben auf dem Sicherheitsdatenblatt. Vorzugweise sind Mittel anzuwenden, bei denen die benutzte Desinfektionsmittellösung über den Abfluss / die Toilette (Anschluss an die öffentliche Abwasserentsorgung) entsorgt werden dürfen.

\subsubsection{Postexpositionsprophylaxe (PEP)}

Im Falle einer Exposition mit Ebolaviren außerhalb von Sonderisolierstationen wird, nach dem Durchführen von Sofortmaßnahmen, eine schnellstmögliche Beratung durch das zuständige STAKOB-Behandlungszentrum, ggf. vermittelt durch das Gesundheitsamt, dringend empfohlen (www.rki.de/stakob).

\section{Lokale Maßnahmen}

- Wenn möglich, sofortige Desinfektion der kontaminierten Stellen mit einem Desinfektionsmittel mit nachgewiesener, mindestens begrenzt viruzider Wirksamkeit.

- Die Hände sind mit einem Händedesinfektionsmittel mit nachgewiesener mindestens begrenzt viruzider Wirksamkeit zu desinfizieren. Diese Mittel können aus pragmatischen Gründen auch zur Desinfektion anderer akzidentell kontaminierter Hautareale angewendet werden. 
- Informationen dazu unter der RKI-Liste, Abschnitt 2.3, der VAH-Liste und der „Empfehlung der Kommission für Krankenhaushygiene und Infektionsprävention beim Robert KochInstitut - Händehygiene“.

- https://www.rki.de/desinfektionsmittelliste

- http://www.vah-online.de/index.php?page=desinfektionsmittel-liste-2

- http://www.rki.de/DE/Content/Infekt/Krankenhaushygiene/Kommission/Downloads/H aendehyg_Rili.pdf

- Zur Schleimhautdesinfektion können Octenidindihydrochlorid/Phenoxyethanol- oder Chlorhexidin-haltige Arzneimittel oder Povidon-lod-Komplexe (7,5\%) entsprechend ihrer zugelassenen Anwendungsgebiete zur Anwendung kommen, z. B. Octenisept, Skinsept mucosa, Braunol. Für die Anwendung am Auge ist $5 \%$ Povidon-lod-Komplex geeignet.

\section{Postexpositionelle Vakzinierung}

- Aktuell gibt es nur für das Zaire-Ebolavirus in Deutschland zugelassene Impfstoffe (siehe auch Informationen des Paul-Ehrlich-Instituts zu Ebola https://www.pei.de/DE/arzneimittel/impfstoffe/ebola/ebola-inhalt.html

- Die Anwendung sollte individuell gemeinsam mit den STAKOB-Behandlungszentren diskutiert werden. Aufgrund der zeitabhängigen Abnahme der mutmaßlichen Effektivität aller antiviraler Ansätze sollte eine Gabe möglichst frühzeitig nach Exposition erfolgen.

- Für eine postexpositionelle Vakzinierung gegen andere Ebola-Spezies (z.B. Ebolavirus Sudan) gibt es zum aktuellen Zeitpunkt keine in Deutschland zugelassenen Impfstoffe.

\section{Postexpositionelle antivirale Prophylaxe}

- Die als erste antivirale Therapeutika bei Ebolavirus Zaire Infektionen in den USA von der FDA zugelassenen Substanzen REGN-EB3/ ImnazebTM und mAB114/ EbangaTM verfügen zum aktuellen Zeitpunkt über keine Zulassung in Deutschland.

- Für die Anwendung als postexpositionelle Prophylaxe dieser Therapeutika gibt es bisher keine Daten. Die Anwendung sollte individuell gemeinsam mit den STAKOBBehandlungszentren diskutiert werden. Aufgrund der zeitabhängigen Abnahme der mutmaßlichen Effektivität aller antiviraler Ansätze sollte eine Gabe möglichst frühzeitig nach Exposition erfolgen.

- Bezüglich der Wirksamkeitsbewertung der einzelnen Substanzen in der Therapie wird auf die „Hinweise zu Therapie und Prophylaxe von Ebolafieber" des STAKOB verwiesen ( www.rki.de/stakob).

- Das bei anderen Erregern von virusbedingten hämorrhagischen Fiebern häufig eingesetzte Ribavirin zeigt gegen Filoviren KEINE Wirkung.

\subsubsection{Präexpositionelle Vakzinierung}

- Derzeit gibt es verschiedene in Europa zugelassene Impfstoffe gegen Ebolavirus-Infektionen, die sich bislang alle gegen Zaire-Ebolavirus richten (rVSV-ZEBOV (ERVEBO) und der 2Dosen-Kombinationsimpfstoff Ad26.ZEBOV (Zabdeno)/MVA-BN-Filo (Mvabea)). Details zu den Wirksamkeits- und Sicherheitsdaten sowie der Impfschemata sind aus den 
entsprechenden Fachinformationen zu entnehmen -

https://www.pei.de/DE/arzneimittel/impfstoffe/ebola/ebola-node.html

- Weitere Kandidaten-Impfstoffe, u.a. gegen Sudan Ebolavirus befinden sich derzeit in Entwicklung.

\subsubsection{Therapie $^{3}$}

Bei Erkrankten erfolgen eine medizinische Behandlung und Isolierung. Die Behandlung beruht vor allem auf ausgedehnten supportiven und ggf. intensivmedizinischen Maßnahmen, unter spezieller Berücksichtigung des Flüssigkeits-, Elektrolyt- sowie Glukosehaushalts sowie ggf. unter Einsatz von spezifischen Therapeutika, je nach ihrer Verfügbarkeit und der zugrunde liegendem Ebola-Spezies.

- Folgende supportive, ggf. intensivmedizinische Maßnahmen stehen zur Verfügung, die in Abhängigkeit vom klinischen Zustand und je nach Kapazität, Schweregrad und Prognose frühzeitig eingeleitet werden sollen (Objektivierung durch geeigneten intensivmedizinischen Score), u.a.:

- Kardiovaskulärem Support;

- Respiratorischem Support;

- Organersatztherapie (Niere, Leber);

- Blutkomponententherapie;

- Entsprechendem engmaschigem Monitoring;

- Die Hydrierung des Erkrankten sollte unter kardiovaskulärem und klinisch-chemischem Monitoring erfolgen.

- Parallel sollten eine Diagnostik und ggf. antimikrobielle Therapie von weiteren Infektionen erfolgen (z.B. obligatorische Malaria-Testung und ggf. Behandlung, bakterielle Superinfektionen etc.).

\section{Spezifische Therapiemöglichkeiten}

- Als erste antivirale Therapeutika bei Ebolavirus Zaire Infektionen wurden in den USA von der FDA REGN-EB3/ ImnazebTM im Oktober 2020 und mAB114/ EbangaTM im Dezember 2020 zugelassen. Da es sich v.a. um spezifische monoklonale Antikörper (-kombinationen) handelt, sind diese gegen andere Ebola-Spezies wahrscheinlich nicht wirksam.

- Beide Substanzen verfügen zum aktuellen Zeitpunkt über keine Zulassung in Deutschland, ihr Einsatz sollte individuell diskutiert werden. Die STAKOB-Behandlungszentren sind untereinander sowie mit der WHO zum fachlichen Austausch vernetzt. Sie stehen jederzeit für eine Beratung zur Therapie und zum klinischen Management zur Verfügung (www.rki.de/stakob).

- Bezüglich der Wirksamkeitsbewertung von einzelnen Substanzen in der Therapie und praktischen Hinweisen zu ihrem Einsatz wird auf die „Hinweise zu Therapie und Prophylaxe von Ebolafieber" des STAKOB verwiesen (www.rki.de/stakob).

\footnotetext{
${ }^{3}$ Eine Arbeitsgruppe zur Therapie des Ebolafiebers aus Mitgliedern des STAKOB, medizinischen Fachgesellschaften, PEI, BfArM und RKI wurde eingerichtet. Diese steht auch für aktuelle Auskünfte zur Therapie zur Verfügung (Kontaktdetails: www.rki.de/stakob)
} 
- Das bei anderen Erregern von virusbedingten hämorrhagischen Fiebern häufig eingesetzte Ribavirin zeigt gegen Filoviren KEINE Wirkung.

\subsubsection{Kriterien für die Entlassung von Ebolafieber-Erkrankten}

Um eine an Ebolafieber erkrankte Person, die sich auf dem Wege der Besserung befindet, von der Sonderisolierstation oder aus dem Krankenhaus zu entlassen, müssen bestimmte Kriterien erfüllt sein, damit durch diese Maßnahme keine Gefahr für andere Personen entsteht.

\section{Empfehlung}

1. Verlegung des Erkrankten auf eine Infektionsstation (Bedingungen vergleichbar mit z. B. der Versorgung von Erkrankten mit offener Lungentuberkulose, auch wenn Ebolaviren im Gegensatz zu Mykobakterien nicht aerogen übertragbar sind, d. h. Vorschleuse, Schutzkleidung), wenn alle vier folgenden Bedingungen erfüllt sind:

- Klinische Symptomatik abgeklungen,

- Person muss absprachefähig sein (psychisch stabil),

- Harn- und Stuhlkontinenz, geformter Stuhl (nach Verlegung Bettstuhl und fachgerechte Entsorgung von Fäzes und Urin),

- PCR-Nachweis im Blut negativ (in 2 unabhängigen Proben im Abstand von $>24$ Stunden).

2. Vollständige Entlassung der Person aus dem Krankenhaus, wenn alle drei folgenden Bedingungen erfüllt sind:

- Alle Punkte wie unter 1,

- Keine Infektiosität in der Zellkultur (in 2 unabhängigen Proben im Abstand von $>24$ Stunden) in Urin, Stuhl, Schweiß, Konjunktivalabstrich und Mundschleimhautabstrich, ggf. Menstruationsblut, bei stillenden Müttern Muttermilch.

- Aufklärung über potentielle Weiterverbreitung der Infektion nach Genesung, insbesondere durch Geschlechtsverkehr. Bei genesenen männlichen Patienten konnte Ebolavirus-RNA in Einzelfällen bis zu 18 Monate nach Beginn der Symptomatik in der Samenflüssigkeit nachgewiesen werden (siehe insbesondere auch Kapitel 4.5).

- Aufklärung über mögliche monatelange Persistenz des Ebolavirus in Körperkompartimenten mit eingeschränkter immunologischer Reaktivität (z.B. Augenkammer, ZNS) und damit einhergehender potentieller Infektiosität der jeweils in den Körperkompartimenten produzierten Körperflüssigkeiten bei invasiven Eingriffen (Operationen, Liquorpunktionen u.a., siehe auch Stellungnahmen des STAKOB www.rki.de/stakob und CDC Interim Guidance for Management of Survivors of Ebola Virus disease)

\subsubsection{Umgang mit Verstorbenen ${ }^{4}$}

\section{Versorgung des Leichnams}

4 Die Empfehlungen zum Umgang mit an Ebolafieber Verstorbenen werden 20189 in Abstimmung mit den Ländern und weiteren Expertinnen und Experten überarbeitet. 
- Tätigkeiten im Umgang mit an Ebolafieber Verstorbenen sollten auf ein Minimum beschränkt sein.

- Manipulationen an der Leiche (z. B. Einbalsamierung) sind nicht zulässig.

- Von einer inneren Leichenschau ist abzusehen. Der Verstorbene sollte unmittelbar nach der erfolgten Leichenschau und evtl. weiteren notwendigen medizinischen Untersuchungen (Gewebeprobe bzw. Blutentnahme) vollständig mit einem speziellen Absorbens bestreut werden. Dieses hat die Eigenschaft, die austretenden Körperflüssigkeiten des Leichnams zu binden, darüber hinaus hat es eine desinfizierende Wirkung.

- Danach ist der Leichnam in zwei formalingetränkte Tücher (10\%ige Lösung) zu hüllen. Anschließend muss der Verstorbene in zwei gut verschließbare, flüssigkeitsdichte Leichenhüllen aus Kunststoff (z. B. innen silbergrau, außen weiß) gelegt werden. Die Verschlüsse dieser Hüllen sind mit flüssigkeitsdichtem Tape zu verkleben bzw. zu versiegeln. Die Hüllen sind danach jeweils von außen mit einem erregergerechten und geeigneten Desinfektionsmittel (RKI-Liste) zu desinfizieren. Nach Ende der Einwirkzeit kann der so verpackte Leichnam ausgeschleust und eingesargt werden.

- Die Leichenhüllen sind (nach VDI-Richtlinien 3891) biologisch abbaubar bei Erdbestattungen und verbrennen rückstandsfrei bei der Feuerbestattung. Kremationen sind der Erdbestattung vorzuziehen. Für die möglichst unverzügliche Kremation ist ein Holzsarg zu verwenden. Der Boden muss mit einer ausreichend hohen Schicht (mindestens $5 \mathrm{~cm}$ ) aufsaugender Stoffe (Sägemehl, Hobelspäne, Vlies u. ä.) bedeckt sein.

- Für das Bestattungspersonal, welches den Leichnam nach den oben genannten Maßnahmen übernimmt, sind somit keine besonderen Schutzmaßnahmen mehr erforderlich.

- Der Sarg muss fest verschlossen und deutlich sichtbar mit einem Biohazard-Zeichen und als "hochinfektiös“ (eigentlich „hochkontagiös") gekennzeichnet sein und bis zur Einäscherung in einem, wenn möglich separaten, auf alle Fälle aber gesicherten und gekühlten Raum aufbewahrt werden.

- Für die Überführung vom Sterbeort zum nächstgelegenen Krematorium ist geschultes Personal erforderlich. Der Transport des Leichnams muss behördlicherseits überwacht werden.

Weitere Informationen finden sich in Eisenmenger et al. 2007.

\section{Kommunikation}

Im Falle des Auftretens von Ebolafieber in Deutschland ist mit einem großen Bedarf an Information und Kommunikation zu rechnen. Je nach Zielgruppe unterscheiden sich dabei die Zuständigkeiten. Eine Koordinierung der Inhalte und Zeitpunkte ist essentiell, um Sorgen und Ängsten entgegenzuwirken.

\subsection{Information der Fachöffentlichkeit}

Aufgrund ihrer exponierten Stellung als Primärversorger und ihrer Rolle als Multiplikatoren sind Ärztinnen und Ärzte (sowohl klinisch tätig als auch im ÖGD) sowie Personal von Polizei, Feuerwehr und Hilfsorganisationen wesentliche Adressaten. Um deren Einsatzfähigkeit zu garantieren und zu 
unterstützen, müssen diese Zielgruppen) zeitnah und umfassend über neue Entwicklungen bezüglich der Lage, der Einschätzung, sowie Risiken und Schutzmaßnahmen informiert werden. Das RKI veröffentlicht auf seiner Internetseite relevante Informationen und Dokumente und aktualisiert diese regelmäßig. Die Kommunikation des ÖGD mit der Ärzteschaft sowie dem Krankenhauspersonal sollte bevorzugt über die Landesärztekammern, die Kassenärztlichen Vereinigungen und die Landeskrankenhausgesellschaften erfolgen.

\section{Vorgehen}

- An die aktuelle Situation angepasste Informationen werden den Zielgruppen zur Verfügung gestellt, z. B. für die spezielle Berufstätigkeit relevante Informationen über Erreger, Schutzmaßnahmen und Gefahrenbeurteilung, Interventionsmaßnahmen und die aktuellen Einsätze. Die Informationen sollten entsprechend den unterschiedlichen Aufgaben und Gegebenheiten auf Bundes-, Landes- und kommunaler Ebene zur Verfügung stehen.

- In der Regel gilt für direkte Anfragen, dass Ärztinnen und Ärzte sich primär an ihr zuständiges Gesundheitsamt wenden sollen (https://tools.rki.de/PLZTool/). Die Gesundheitsämter wenden sich an die zuständigen Landesbehörden, und diese wiederum kommunizieren mit den Bundesbehörden, z. B. dem RKI.

\subsection{Information der Bevölkerung und Medien}

Im Fall des Auftretens von Ebolafieber in Deutschland ist von einer großen Verunsicherung der Bevölkerung auszugehen. Durch zeitnahe, sachliche, transparente Information muss dem soweit wie möglich entgegengewirkt werden. Insbesondere muss die Bevölkerung über die realistischen Risiken und - die nur bei engem Kontakt zu Erkrankten erforderlichen - Schutzmaßnahmen informiert werden.

\section{Vorgehen}

- Die Bewältigung von Krisensituationen durch Ausbrüche übertragbarer Erkrankungen hängt wesentlich davon ab, wie die Behörden mit der Bevölkerung kommunizieren. Zu den Zielen der Kommunikation zählt die Minimierung des Auftretens von Krankheitsfällen in Deutschland, ebenso wie die Vermeidung von Überreaktionen, die zu Unruhe und im Einzelfall problematischen Einschränkungen in der medizinischen Versorgung von Personen aus betroffenen Regionen führen könnten (z.B. weil sie als vermeintliche Ebolafieber-Verdachtsfälle angesehen werden, obwohl sie gar nicht in einer Region mit Ebola waren). Es ist davon auszugehen, dass im Falle des Auftretens einzelner oder weniger Ebolafieber-Fälle in Deutschland eine großflächige Weiterverbreitung in der Bevölkerung praktisch auszuschließen ist, da in Deutschland alle Voraussetzungen zur Unterbrechung von Infektionsketten und zur sicheren Versorgung der Betroffenen gegeben sind. Auf Basis der fachlichen Erkenntnisse und angepasst an die spezifische Lage sollten der Bevölkerung sinnvolle und effektive Präventionsmaßnahmen vermittelt werden. Dies erfordert flexible, an die aktuelle epidemiologische Situation angepasste Kommunikationsmittel und -wege.

- Eine erfolgreiche Motivation der Bevölkerung zur Umsetzung der empfohlenen Maßnahmen hängt maßgeblich davon ab, dass die Zielgruppe die Quelle der Information bzw. den Sender der Botschaft als vertrauenswürdig einstuft. Dafür ist es wichtig, zeitnah über neue Erkenntnisse zu informieren, bestehende Ängste anzusprechen und 
Unsicherheiten klar zu benennen. Es kann notwendig sein, besonders gefährdete oder schwer zu erreichende Gruppen durch zielgruppenspezifische Kommunikationsstrategien anzusprechen. Multiplikatoren für die Kommunikation mit der Bevölkerung sind (Fach-) Öffentlichkeit und Medien.

- Widersprüchliche Kommunikation durch unterschiedliche Akteure muss vermieden werden. Auf die Abstimmung zwischen den Behörden und Institutionen geht die Allgemeine Verwaltungsvorschrift über die Koordinierung des Infektionsschutzes (IfSGKoordinierungs-VWV) in epidemisch bedeutsamen Fällen in $\int 10$ folgendermaßen ein:

„(1) Ein wesentlicher Teilbereich der Bewältigung einer epidemisch bedeutsamen Lage ist die externe Kommunikation der Behörden mit

1. den gesundheitlich betroffenen Bevölkerungsgruppen,

2. der medizinischen Fachöffentlichkeit,

3. weiteren betroffenen Akteuren,

4. der allgemeinen Öffentlichkeit und

5. den Medien.

(2) Die zuständigen Behörden achten darauf, dass die Kommunikation mit den in Absatz 1 genannten Gruppen möglichst einheitlich ist und deren jeweiligen

Informationsbedürfnissen entspricht. Die Behörden sollen die Lage, ihre Bewertung, die Ermittlungen sowie die Maßnahmen einschließlich Verhaltensempfehlungen, deren Zustandekommen und ihre Gründe kontinuierlich, nachvollziehbar und reaktionsschnell vermitteln. Der Umfang der Kommunikation ist an die Gefahrenlage sowie an das erwartete öffentliche und mediale Interesse anzupassen." (Allgemeine Verwaltungsvorschrift über die Koordinierung des Infektionsschutzes in epidemisch bedeutsamen Fällen (IfSG-Koordinierungs-VwV, 2013))

\subsection{Internationale Kooperation}

Die durch einen Ausbruch im Ausland bestehenden, wenn auch geringen Risiken für die Bevölkerung in Deutschland können nur durch eine effektive und zeitnahe Bekämpfung des Ausbruchs vor Ort maßgeblich und nachhaltig reduziert werden.

Der Mangel an eigenen Kapazitäten in anderen Staaten (Isolierstationen, S4-Labore, Isoliertransporte / Repatriierung) bzw. die Betroffenheit anderer Staaten durch das Infektionsgeschehen machen internationale Kooperation notwendig. Es ist im Interesse der einzelnen Staaten, dass die Eindämmung der Gefahr im Ausland unterstützt wird, damit die innerstaatlichen Bemühungen nicht durch importierte oder reimportierte Fälle erschwert werden.

Vorgehen

- Gegenseitige Information (Internationale Gesundheitsvorschriften (ICV), Global Health Security Initiative (GHSI), Early Warning and Response System (EWRS)).

- Aktive Beteiligung in internationalen Arbeitsgruppen zur Erstellung gemeinsamer Strategien.

- Austausch und Abstimmung von Empfehlungen und Strategiepapieren mit anderen Staaten. 
- Identifikation der erforderlichen / möglichen Hilfeleistungen (z. B. medizinische Ressourcen, Experten etc.).

\section{Evaluierung}

Im Anschluss an eine außergewöhnliche biologische Gefahrenlage ist die Nachbereitung als Struktur-, Prozess- und Ergebnisevaluation auf allen beteiligten Ebenen nötig. Wichtig bei diesem Prozess ist in erster Linie der horizontale und vertikale Austausch der Erfahrungen unter den betroffenen Akteurinnen und Akteuren. Die WHO und das ECDC empfehlen sog. In(tra)- und AfterAction Reviews (IAR/AAR), um Lehren aus einem Geschehen zu ziehen und die Krisenreaktion in Zukunft zu verbessern. Dabei handelt es sich bei IAR/AARs um kollektive, kontinuierliche Lernprozesse, die relevante Akteurinnen und Akteure zusammenbringen, um kritisch und systematisch bisherige Maßnahmen zur Bewältigung einer Gesundheitskrise zu analysieren.

Vorgehen

Mögliche Methoden sind:

- IAR/AAR,

- Workshops / Fokusgruppen mit Ergebnis-Berichten,

- Abschlussbericht (am Bsp. Infektionsepidemiologie) nach Ende des Ausbruches:

- Epidemiologischer Hintergrund,

- Fallbeschreibung/Ausbruchsdarstellung,

- Liste der Erkrankungsfälle sowie der ermittelten Kontaktpersonen (z. B. aus Übermittlungssoftware) mit Angaben zu Geschlecht, Geburtsjahr, Auftritt der Erkrankung, Impfstatus, Laborergebnisse, klinischer Verlauf/Komplikationen,

- Kritische Bewertung des Fall- bzw. Ausbruchsmanagements,

- Beschreibung ergriffener Maßnahmen und Bewertung des Nutzens,

- Kritische Bewertung des Rahmenkonzepts/vorhandener Seuchenalarmpläne,

- Ggf. Kostenkalkulation (Aufwand für intensivierte Surveillance, Labor, Kommunikation, Training, Transport etc.),

- Wissenschaftliche Aufarbeitung / Publikationen. 


\section{Abkürzungsverzeichnis}

\begin{tabular}{|c|c|}
\hline AAR & After-Action Review \\
\hline ABAS & Ausschuss für Biologische Arbeitsstoffe \\
\hline ADR & $\begin{array}{l}\text { Europäische Übereinkommen über die internationale Beförderung gefährlicher Güter } \\
\text { auf der Straße (Accord européen relatif au transport international des marchandises } \\
\text { Dangereuses par Route) }\end{array}$ \\
\hline AS & Abfallschlüssel \\
\hline BMG & Bundesministerium für Gesundheit \\
\hline BNITM & Bernhard-Nocht-Institut für Tropenmedizin \\
\hline$B Z g A$ & Bundeszentrale für gesundheitliche Aufklärung \\
\hline CDC & Centers for Disease Control and Prevention \\
\hline DG SANCO & European Commission Health and Consumer Protection Directorate General \\
\hline EAK & Europäischer Abfallkatalog \\
\hline ECDC & European Centre for Disease Prevention and Control \\
\hline EDV & Elektronische Datenverarbeitung \\
\hline ELISA & Enzyme Linked Immunosorbent Assay \\
\hline EpiLag & Epidemiologische Lagekonferenz \\
\hline EU & Europäische Union \\
\hline EVD & Ebola Virus Disease \\
\hline EWRS & “Early Warning and Response System” der EU \\
\hline $\mathrm{FFP}_{3}$ & Partikelfiltrierende Atemschutzmaske 3, wobei " 3 " für die Klasse steht \\
\hline GHSI & Global Health Security Initiative \\
\hline GIS & Geoinformationssystem \\
\hline GMLZ & Gemeinsames Melde- und Lagezentrum von Bund und Ländern \\
\hline HEPA & High Efficiency Particulate Air \\
\hline HIV & Humanes Immundefizienz-Virus \\
\hline IAR & In(tra)- Action Review \\
\hline IATA & International Air Transport Association \\
\hline IF & Immunfluoreszenz \\
\hline IfSG & Infektionsschutzgesetz \\
\hline $\operatorname{lgG} / \mathrm{M}$ & Immunglobulin G/M \\
\hline IGV & Internationale Gesundheitsvorschriften \\
\hline IGV-DG & Gesetz zur Durchführung der Internationalen Gesundheitsvorschriften (2005) \\
\hline IRTW & Infektions-Rettungswagen \\
\hline IT & Informationstechnik \\
\hline LAGA & Bund/Länder-Arbeitsgemeinschaft Abfall \\
\hline NT & Neutralisationstest \\
\hline o. ä. & oder ähnlichem \\
\hline
\end{tabular}




$\begin{array}{ll}\text { ÖGD } & \text { Öffentlicher Gesundheitsdienst } \\ \text { PCR } & \text { Polymerase Chain Reaction / Polymerase-Kettenreaktion } \\ \text { PEP } & \text { Postexpositionsprophylaxe } \\ \text { PSA } & \text { Persönliche Schutzausrüstung } \\ \text { RKI } & \text { Robert Koch-Institut } \\ \text { SAV } & \text { Sonderabfallverbrennungsanlage } \\ \text { S3/S4-Labor } & \text { Laboreinrichtung der Schutzstufe 3 bzw. 4 (nach Biostoffverordnung) } \\ \text { STAKOB } & \text { Ständiger Arbeitskreis der Kompetenz- und Behandlungszentren für Krankheiten } \\ & \text { durch hochpathogene Erreger } \\ \text { SVD } & \text { Sudan Virus Disease } \\ \text { TRBA } & \text { Technische Regel für Biologische Arbeitsstoffe } \\ \text { VHF } & \text { Virale hämorrhagische Fieber } \\ \text { VAH } & \text { Verbund für Angewandte Hygiene } \\ \text { VwV } & \text { Verwaltungsvorschrift } \\ \text { WHO } & \text { World Health Organisation / Weltgesundheitsorganisation }\end{array}$




\section{Weiterführende Literatur}

1. Baggi FM, Taybi A, Kurth A, et al.: Management of pregnant women infected with Ebola virus in a treatment centre in Guinea, June 2014. Eurosurveillance 2014; 19(49).

2. Baron RC, McCormick MJ, Zubeir OA: Ebola virus disease in southern Sudan: hospital dissemination and intrafamiliar spread. Bull WHO 1983;61:997-1003.

3. Bausch DG, Towner JS, Dowell SF, et al.: Assessment of the risk of Ebola virus transmission from bodily fluids and fomites. J Infect Dis. 2007; 196 (Supplement 2): S142-S147.

4. Calisher $\mathrm{H}$, Childs JE, Fields HE, et al.: Bats: Important reservoir hosts of emerging viruses. Clinical Microbiology Reviews, July 2006, p. 531-545 Vol. 19, No. 3.

5. Centers for Disease Control and Prevention: Case Definition for Ebola Virus Disease EVD), updated August 7, 2014. http://www.cdc.gov/vhf/ebola/hcp/case-definition.html.

6. Centers for Disease Control and Prevention: Interim Guidance for Managing Patients with Suspected Viral Hemorrhagic Fever in U.S. Hospitals. 2005.

7. Centers for Disease Control and Prevention: Interim Guidance for Management of Survivors of Ebola Virus Disease in U.S. Healthcare Settings, Page last reviewed: May 7, 2021, https://www.cdc.gov/vhf/ebola/clinicians/evaluating-patients/guidance-for-management-ofsurvivors-ebola.html

8. Chertow DS, Kleine C, Edwards JK, et al.: Ebola virus disease in West Africa - Clinical manifestations and management. N Engl J Med. 2014 November 5.

9. Chughtai, A: Persistance of Ebola virus in various body fluids during convalescence: evidence and implications for disease transmission and control. Doi:

doi:10.1017/So950268816000054

10. CIDRAP: UK nurse with Ebola meningitis released from isolation, 12 Nov 2015, http://www.cidrap.umn.edu/news-perspective/2015/11/uk-nurse-ebola-meningitis-releasedisolation.

11. Deen GF, Broutet N, Xu W, et al.: Ebola RNA Persistence in Semen of Ebola Virus Disease Survivors — Final Report, N Engl J Med 2017; 377:1428-1437, DOI: 10.1056/NEJMoa1511410

12. Drosten, $\mathrm{C}$, Kümmerer BM, Schmitz H, et al.: Molecular diagnostics of viral hemorrhagic fevers. Antiviral Research 2003; 57:61-87.

13. Eisenmenger W, Gillich R, Graf P, et al.: Maßnahmen bei Todesfall an gemeingefährlichen Infektionserregern. Handbuch Biologische Gefahren I 2007. Hrg.: BBK und RKI. 509-517.

14. European Centre for Disease Prevention and Control: Risk assessment guidelines for diseases transmitted on aircraft. 2nd ed. Stockholm: ECDC; 2010.

http://www.ecdc.europa.eu/en/publications/publications/1012_gui_ragida_2.pdf. 
15. Falldefinitionen des Robert Koch-Instituts zur Übermittlung von Erkrankungs- oder Todesfällen und Nachweisen von Krankheitserregern http://www.rki.de/DE/Content/Infekt/IfSG/Falldefinition/falldefinition_node.html

16. Fisher-Hoch SP, Platt GS, Neild GH, et al.: Pathophysiology of shock and hemorrhage in a fulminating viral infection (Ebola). J Infect Dis 1985; 152(5):887-94.

17. Fock R, Koch U, Finke EJ, et al.: Schutz vor lebensbedrohenden importierten Infektionskrankheiten. Bundesgesundheitsbl - Gesundheitsforsch - Gesundheitsschutz 2000; 43: 891-899.

18. Fock $R$, Koch $U$, Wirtz $A$, et al.: Erste medizinische und antiepidemische Maßnahmen bei Verdacht auf virales hämorrhagisches Fieber. Med Welt 2001; 52:126-132.

19. Fock R, Wirtz A, Peters M, et al.: Management und Kontrolle lebensbedrohender hochkontagiöser Infektionskrankheiten. Bundesgesundheitsbl - Gesundheitsforsch Gesundheitsschutz 1999; 42: 389-401.

20. Garske T, Cori A, Ariyarajah A, et al: Heterogeneities in the case fatality ratio in the West African Ebola outbreak 2013-2016, Philos Trans R Soc Lond B Biol Sci. 2017 May 26; 372 (1721): 20160308. Published online 2017 Apr 10. doi: 10.1098/rstb.2016.0308.

21. Hayman DT, Yu M, Crameri G, et al.: Ebola virus antibodies in fruit bats, Ghana, West Africa. Emerg Infect Dis. 2012 Jul;18(7):1207-9.

22. Henao-Restrepo AM, Longini IM, Egger M, et al.: Efficacy and effectiveness of an rVSVvectored vaccine expressing Ebola surface glycoprotein: interim results from the Guinea ring vaccination cluster-randomised trial, Lancet 2015 August 3 (online), http://dx.doi.org/10.1016/So140-6736(15)61117-5.

23. Jacobs $M$, Rodger A, Bell DJ, et al.: Late Ebola virus relapse causing meningoencephalitis: a case report. Lancet. 2016 Jul 30;388(10043):498-503. doi: 10.1016/So140-6736(16)30386-5. Epub 2016 May 18.

24. Keita AK, Vidal N, Toure A, et al.: PostEbogui Study Group. A 40-Month Follow-Up of Ebola Virus Disease Survivors in Guinea (PostEbogui) Reveals Long-Term Detection of Ebola Viral Ribonucleic Acid in Semen and Breast Milk. Open Forum Infect Dis. 2019 Nov 8;6(12):ofz482. doi: 10.1093/ofid/ofz482. PMID: 32128327; PMCID: PMC7047953.

25. Keita AK, Koundouno FR, Faye M, et al.: Resurgence of Ebola virus in 2021 in Guinea suggests a new paradigm for outbreaks. Nature. 2021 Sep;597(7877):539-543. doi: 10.1038/s41586-021-03901-9. Epub 2021 Sep 15. PMID: 34526718.

26. Kreuels B, Wichmann D, Emmerich P, et al.: A case of severe Ebola virus infection complicated by gram-negative septicemia. N Engl J Med. 2014 December 18; 371:2394-2401.

27. Moreau M, Spencer C, Gozalbes JG, et al.: Lactating mothers infected with Ebola virus: EBOV RT-PCR of blood only may be insufficient. Euro Surveill. 22 January 2015;20(3):pii=21017. 
28. NIH: Experimental Ebola Drug ZMapp May Benefit Patients, but Insufficient Data to be Certain, Study Finds, 23 Feb 2016, https://www.niaid.nih.gov/news-events/experimentalebola-drug-zmapp-may-benefit-patients-insufficient-data-be-certain-study.

29. Piercy TJ, Smither SJ, Steward JA, et al.: The survival of filoviruses in liquids, on solid substrates and in a dynamic aerosol. J Appl Microbiol. 2010 Nov;109(5):1531-9.

30. Prescott J, Bushmaker T, Fischer R, et al.: Postmortem stability of Ebola virus. Emerg Infect Dis 2015. Vol. 21 No. 5 (May 2015). http://dx.doi.org/10.3201/eid2105.150041.

31. Rampling T, Ewer K, Bowyer G, et al.: A monovalent chimpanzee Adenovirus Ebola vaccine Preliminary report. N Engl J Med. 2015 January 28.

32. Rodriguez LL, De Roo A, Guimard Y, et al.: Persistence and genetic stability of Ebola virus during the outbreak in Kikwit, Democratic Republic of the Congo, 1995. J Infect Dis 1999; 179(Suppl 1):S170-6.

33. Schieffelin JS, Shaffer JG, Goba A, et al.: Clinical illness and outcomes in patients with Ebola in Sierra Leone. N Engl J Med. 2014 October 29.

34. Scott, J: Post-Ebola Syndrome, Sierra Leone. Doi: 10.3201/eid2204.151302

35. Sissoko D, Laouenan C, Folkesson E et al.: Experimental treatment with Favipiravir for Ebola Virus Disease (the JIKI Trial): A historically controlled, single-arm proof-of-concept trial in Guinea, PLoS Med. 2016 Mar 1;13(3):e1001967. doi: 10.1371/journal.pmed.1001967. eCollection 2016.

36. STAKOB: Stellungnahmen des STAKOB zu Ebola, www.rki.de/stakob-stellungnahmen,

37. van Herp M, Declerck H, Decroo T: Favipiravir-a prophylactic treatment for Ebola contacts? Lancet 2015 June 13 (correspondence), http://www.thelancet.com/pdfs/journals/lancet/PIISO140-6736\%2815\%2961095-9.pdf\%2O.

38. Varkey JB, Shantha JG, Crozier I, et al.: Persistence of Ebola virus in ocular fluid during convalescence. N Engl J Med. 2015 June 18; 372:2423-2427.

39. Vetter $P$, Kaiser L, Schibler M, et al.: Sequelae of Ebola virus disease: the emergency within the emergency, The Lancet Infectious Diseases, Volume 16, Issue 6, June 2016, Pages e82e91

40. WHO: Guidelines for the management of pregnant and breastfeeding women in the context of Ebola virus disease, 16 February 2020, https://www.who.int/publications/i/item/9789240001381, abgerufen 12.11.2022

41. WHO Media Centre Fact Sheet Ebola Virus Disease, 23 February 2021, http://www.who.int/mediacentre/factsheets/fs103/en/, abgerufen 12.11.2022

42. WHO Statement on the $1^{\text {st }}$ Meeting of the International Health Regulations Emergency Committee on the 2014 Ebola Outbreak in West Africa, 8 August 2014, https://www.who.int/news/item/08-08-2014-statement-on-the-1st-meeting-of-the-ihremergency-committee-on-the-2014-ebola-outbreak-in-west-africa . 
43. Wolf T, Kann G, Becker S, et al.: Severe Ebola virus disease with vascular leakage and multiorgan failure: Treatment of a patient in intensive care. Lancet 2015 April 11, 385:1428-35.

44. Wood JL, Leach M, Waldman L, et al.: A framework for the study of zoonotic disease emergence and its drivers: Spillover of bat pathogens as a case study. Philos Trans R Soc Lond B Biol Sci. 2012 Oct 19;367(1604):2881-92. 


\section{Anlagen}

Anlage A - Infografik: Maßnahmen bei Verdacht auf Ebolafieber $\underline{\text { www.rki.de/ebola-flussschema }}$

Anlage B - Liste der Kompetenz- und Behandlungszentren für Krankheiten durch hochpathogene Erreger mit Zuständigkeitsbereichen nach Region www.rki.de/stakob

Anlage C - Hinweise zur Malaria-Diagnostik und zur Interpretation von Malaria-Befunden bei einer in den letzten 21 Tagen aus Ebolafieber-Ausbruchsländern eingereisten Person, die sich noch nicht in einem der Behandlungszentren befindet

www.rki.de/ebola-malariadiagnostik

Anlage D - Hinweise zur Labordiagnostik bei Verdacht auf Ebolafieber www.rki.de/ebola-labordiagnostik

Anlage $\mathrm{E}$ - Biologische Arbeitsstoffe im Gesundheitswesen und in der Wohlfahrtspflege (TRBA 250) http://www.baua.de/de/Themen-von-A-Z/Biologische-Arbeitsstoffe/TRBA/TRBA-250.html

Anlage F - ABAS-Beschluss 610 Schutzmaßnahmen für Tätigkeiten außerhalb von Sonderisolierstationen bei der Versorgung von Patienten, die mit hochpathogenen Krankheitserregern infiziert oder krankheitsverdächtig sind https://www.baua.de/DE/Angebote/Rechtstexte-und-TechnischeRegeln/Regelwerk/TRBA/Beschluss-610.html

Anlage G - Schutzmaßnahmen für Tätigkeiten mit biologischen Arbeitsstoffen in Laboratorien (TRBA 100) www.baua.de/de/Themen-von-A-Z/Biologische-Arbeitsstoffe/TRBA/TRBA-100.html

Anlage $\mathrm{H}$ - Mustervorschlag Kontaktpersonenliste www.rki.de/ebola-kontaktpersonen-liste

Anlage I - Mustervorschlag Differenzierung von Kontaktpersonen zu einem Ebolafieber-Fall (oder -Verdachtsfall) nach Risiko und Tagebuch zu auftretenden Symptomen innerhalb der Inkubationszeit

$\underline{\text { www.rki.de/ebola-kontaktpersonen-tagebuch }}$

Anlage J - Empfohlene Maßnahmen für medizinisches und anderes Personal, das in der Patientenversorgung oder Ausbruchsbekämpfung im Rahmen eines Ebolafieberausbruchs tätig war $\underline{w w w . r k i . d e / h i l f s k r a e f t e}$

Anlage K - Umgang von Zollbehörden mit Paket- und Frachtsendungen aus EbolafieberEndemiegebieten www.rki.de/ebola-zollbehoerden

Anlage L - Maßnahmen zur Desinfektion und Abfall-/Abwasserentsorgung im Zusammenhang mit einem begründeten Ebolafieber-Verdachtsfall in Deutschland www.rki.de/ebola-desinfektion 
Anlage M - Vollzugshilfe zur Entsorgung von Abfällen aus Einrichtungen des Gesundheitsdienstes (Bund/Länder-Arbeitsgemeinschaft Abfall (LAGA)) www.rki.de/DE/Content/Infekt/Krankenhaushygiene/Kommission/Downloads/LAGA-Rili.pdf

\section{Anlage N -}

Multilaterale Vereinbarung M315 nach Abschnitt 1.5.1 von Anlage A des ADR betreffend die Beförderung von Abfall, der mit hämorrhagisches Fieber auslösenden Viren verunreinigt ist https://www.unece.org/trans/danger/multi/multi.html

Anlage O - Musteranleitung für das Verpacken nach MV 281 mit zusätzlichen Optionen / Übergabe von ansteckungsgefährlichen Abfällen zum Transport UN 2814 (Ebola)

www.rki.de/ebola-verpackungsanleitung

Anlage P - Musterbeförderungspapier. Beförderung vereinbart nach Abschnitt 1.5.1 des ADR (M315) www.rki.de/ebola-musterbefoerderungspapier

Anlage Q - Mustersicherungsplan für UN 2814. Maßnahmen zur Sicherung / Vermeidung von Risiken gemäß Unterabschnitt 1.10.3.2 ADR / RID

www.rki.de/ebola-mustersicherungsplan 